\title{
Models of Mantle Convection Incorporating Plate Tectonics: The Australian Region since the Cretaceous
}

\author{
Michael Gurnis \\ Seismological Laboratory, California Institute of Technology \\ Louis Moresi \\ Australian Geodynamics Cooperative Research Centre, CSIRO Exploration and Mining \\ R. Dietmar Müller \\ Department of Geology and Geophysics, The University of Sydney
}

We propose that the anomalous Cretaceous vertical motion of Australia and distinctive geochemistry and geophysics of the Australian-Antarctic Discordance (AAD) were caused by a subducted slab which migrated beneath the continent during the Cretaceous, stalled within the mantle transition zone, and is presently being drawn up by the Southeast Indian Ridge. During the Early Cretaceous the eastern interior of the Australian continent rapidly subsided, but must have later uplifted on a regional scale. Beneath the AAD the mantle is cooler than normal, as indicated by a variety of observations. Seismic tomography shows an oblong, slab-like structure orientated N-S in the transition zone and lower mantle, consistent with an old subducted slab. Using a three-dimensional model of mantle convection with imposed plate tectonics, we show that both of these well documented features are related. The models start with slabs dipping toward the restored eastern Australian margin. As Australia moves east in a hot spot reference frame from 130-90 Ma, a broad dynamic topography depression of decreasing amplitude migrates west across the continent causing the continent to subside and then uplift. Most of the slab descends into the deeper mantle, but the models show part of the cooler mantle becomes trapped within the transition zone. From $40 \mathrm{Ma}$ to the present, wisps of this cool mantle are drawn up by the northwardly migrating ridge between Australia and Antarctica. This causes a circular dynamic topography depression and thinner crust to develop at the present position of the AAD. The AAD is unique

The History and Dynamics of Global Plate Motions

Geophysical Monograph 121

Copyright 2000 by the American Geophysical Union 
within the ocean basins because it is the only place where a modern ridge has migrated over the position of long term Mesozoic subduction. Our study demonstrates the predictive power of mantle convection models when they incorporate plate tectonics.

\section{INTRODUCTION}

Mantle convection is the means by which heat is removed from the deep interior of the planet. Plate tectonics defines the dominant mode of mantle convection and subduction is responsible for creating most density heterogeneity within the mantle as imaged by seismic tomography. The oceanic lithosphere is part of mantle convection and the plates drive themselves through a combination of the buoyancy force associated with cooling oceanic lithosphere (often referred to as ridge push) and subducting oceanic lithosphere (slab pull). There is now little serious debate concerning the dynamics controlling first order features of instantaneous plate kinematics. It is now time to move on to equally important but unsolved problems in mantle dynamics, including why we have plate tectonics (as opposed to some other tectonic mode which would remove planetary heat), what controls the time-dependence of mantle convection, and the connection between mantle dynamics and the wide range of observations which convection models have not traditionally been compared with. In this paper, we describe a regional study pertaining to the latter class of problems: what is the timedependent nature of mantle convection as constrained by geological and geochemical observations?

From plate kinematics, we know that mantle convection must be time-dependent. At the largest-scale, all continents aggregated during the Late Paleozoic into a single supercontinent, Pangea, and then dispersed during the Mesozoic [Van der Voo, 1993]. There was probably at least one earlier supercontinent, referred to as Rodinia [Dalziel, 1992]. On a somewhat smaller scale, $\approx 43$ $\mathrm{Ma}$ ago, the Pacific plate apparently changed direction from a northerly to a westerly direction [Engebretson et $a l, 1985]$. During the Cenozoic, there has been extensive trench rollback of oceanic trenches [Chase, 1978] and ridge jumps [Mammerickx and Sandwell, 1986]. Since plate tectonics is a clear expression of mantle convection, these time-dependent aspects of plate kinematics must represent time-dependent mantle convection there must be causes and consequences of these surface phenomena in the Earth's mantle. In fact, it is hard to imagine that such time-dependent convection would not be associated with the vertical motion of mantle buoyancy forces. Beyond the kinematic evidence, it is generally believed that we have limited direct observational constraints on time-dependent mantle convection.
In this paper, we have focused on the Australian plate because there are large-scale features which cannot be explained by application of plate tectonics, but which may be associated with the radial motion of buoyancy within the mantle. The two perplexing features which we focus on here include the complete subaerial exposure of the Australian continent (i.e. a regional sea-level minimum) during the Cretaceous global sea level maximum and the existence of a cold spot, often interpreted as a convective down welling, beneath the AustralianAntarctic spreading center. Without considering the ultimate cause, Veevers [1982] had earlier suggested that these two features were related. Here, we will specifically argue that the two features are related to the overriding of an ancient, long-lived subduction zone by the Australian plate. With the use of numerical models of mantle convection, we will argue that anomalous sea-level fluctuations, sea-floor depths, isotopic variations, and lower mantle seismic variations, can be understood within the context of time-dependent mantle convection. We show that a range of reasonable models can easily account for the overall features of Australian vertical motion and a localized topographic depression ranging from 200 to $800 \mathrm{~m}$ in the present position of the AAD. The implication of this regionally focussed study is that disparate data types can be understood within the context of time-dependent mantle convection when convection models are explicitly tailored to observed paleogeography.

This paper is organized in the following manner. We first describe the stratigraphic, marine geophysical and geochemical, and seismic tomography observations which characterize this region. These observations dictate the kinds of predictions we will attempt to make from our forward models and consequently how such models should be formulated. Since the forward models will be initial and boundary value problems, the results are dependent on the paleogeography of the Australian region. We describe the model formulation including some of the technical challenges and limitations of our approach. We systematically step through a single computation in terms of physical processes and associated predictions. However, we show that the predictions are dependent on both intrinsic unknowns of the mantle (like mantle viscosity) and uncertainties in paleogeography. An abbreviated dsecription of our worked appeared in Gurnis et al. [1998]. 


\section{AUSTRALIAN VERTICAL MOTION}

Considerable insight can be gained into the timedependence of mantle convection, especially the temporal evolution of slab structure, by looking at the vertical motion of continents, either the motion of one continent with respect to others or the tilting within a single continent [Gurnis, 1992]. The vertical motion of the Earth's surface associated with the rearrangement of mantle buoyancy forces have rates generally less than $100 \mathrm{~m} / \mathrm{Myr}$. Consequently, we must rely on observations from sedimentary geology to constrain such motions [Gurnis, 1992]. Unfortunately, stratigraphic architecture depends on a number of variables, including sediment supply, climate, eustasy (or global sea-level), and local or regional vertical motions. Consequently, the best proxies for continental vertical motion come from relative sea-level (RSL) change, often observed as anomalous marine inundation of one continent with respect to the mean inundation of all continents [Hallam, 1992]. One of the best examples of such motion is the anomalous subsidence of the western United States during the Cretaceous [Bond, 1976; Cross and Pilger, 1978; Mitrovica et al., 1989] which has been quantitatively linked first to a shallowing dip angle of the Farallon plate subducting beneath North America and the subsequent uplift associated with the demise of subduction [Mitrovica et al., 1989; Burgess et al., 1997; LithgowBertelloni and Gurnis, 1997] .

Australia shows substantial oddities in the pattern of marine inundation which have been linked to the vertical motion of that continent. During the Cretaceous, the marine inundation of Australia and global (e.g. eustatic) sea-level curves are out of phase (Fig. 1A). Maximum flooding of Australia occurred in the Late Aptian to Early Albian, 120-110 Ma [Paine, 1990; Struckmeyer and Brown, 1990], when large fractions of the craton, especially in the east, and margins experienced marine inundation (Fig. 1C). During the Late Cretaceous, Australia became progressively exposed, with a flooding minimum in the Campanian, 80-70 Ma, when eustatic sea-level was inferred to be near a maximum [Veevers, 1984]. Relative sea-level curves of Australian basins are also discrepant; inundation curves for the western margin of Australia resemble eustatic sea level curves, while inundation inferred from the Eromanga and Surat Basins in the east correlate poorly with eustatic variations [Stuckmeyer and Brown, 1990]. The Eromanga and Surat Basins (dashed line, Fig. 1C) are part of an extensive intracratonic basin system containing up to $3.5 \mathrm{~km}$ of Cretaceous and Jurassic sediments and occupy a combined area of $1.5 \times 10^{6} \mathrm{~km}^{2}$ [Exon and Senior, 1976].
These apparently incongruous relative sea-level curves support the hypothesis that Australia experienced several episodes of craton-wide vertical motion as well as regional vertical movement during the Cretaceous [Veevers, 1984]. Estimates of Australian vertical motion indicate the occurrence of both a large-scale vertical translation of the entire continent and a regional subsidence event [Veevers, 1984; Bond, 1976; Russell and Gurnis, 1994]. Firstly, during the Early Cretaceous, the vertical motion appears to have been confined to a smaller portion of the east in the area defined by the Eromanga and Surat Basins. Secondly, near the end of the Cretaceous, Australia, was approximately $250 \mathrm{~m}$ higher than it is today (Fig. 1B). Some time during the Cenozoic, Australia appears to have subsided as a single unit, perhaps with very little tilting [Russell and Gurnis, 1994], as the continent moved northward after it separated from Antarctica.

Superimposed on this continent wide motion is the subsidence and subsequent uplift of the Eromanga Basin, specifically, and the eastern margin, generally. The Eromanga Basin, slowly subsiding during the Jurassic, experienced a rapid pulse of subsidence at $100 \mathrm{Ma}$, amounting to $500 \mathrm{~m}$ of tectonic subsidence in $10 \mathrm{Myr}$ [Gallagher and Lambeck, 1989]. This rapid subsidence is well displayed through the detailed geohistory analysis of Gallagher and Lambeck [1989] for the Walkandi-1 borehole within the western portion of the Eromanga Basin (Fig. 2). Many of the sediments from the Early Cretaceous are marine and associated with a general marine incursion. During the end of the Early Cretaceous, marine sediments alternate with non-marine (volcano-clastics derived from the eastern margin), followed by a depositional hiatus when global sea level was highest [Gallagher and Lambeck, 1989]. The thermal history of sediments inferred from apatite fission tracks suggest that the Cretaceous section was probably deposited, but has since been eroded in both the Surat Basin and the basins directly on the eastern margin [Gallagher et al., 1994]. This is consistent with the tilting up toward the east of marine strata of areas which were at or below sea level during the Cretaceous [ $\mathrm{Gal}$ lagher et al., 1994; Russell and Gurnis, 1994].

\section{PRESENT DAY STATE OF THE AUSTRALIAN REGION}

The present day physical and chemical state of a region complements the constraints on mantle convection provided by relative sea-level change. Residual topography, the geoid, and seismic structure have been used to constrain mantle convection in a number of previous studies and we present an overview of such observations 


\section{A. Eustasy \& Flooding}

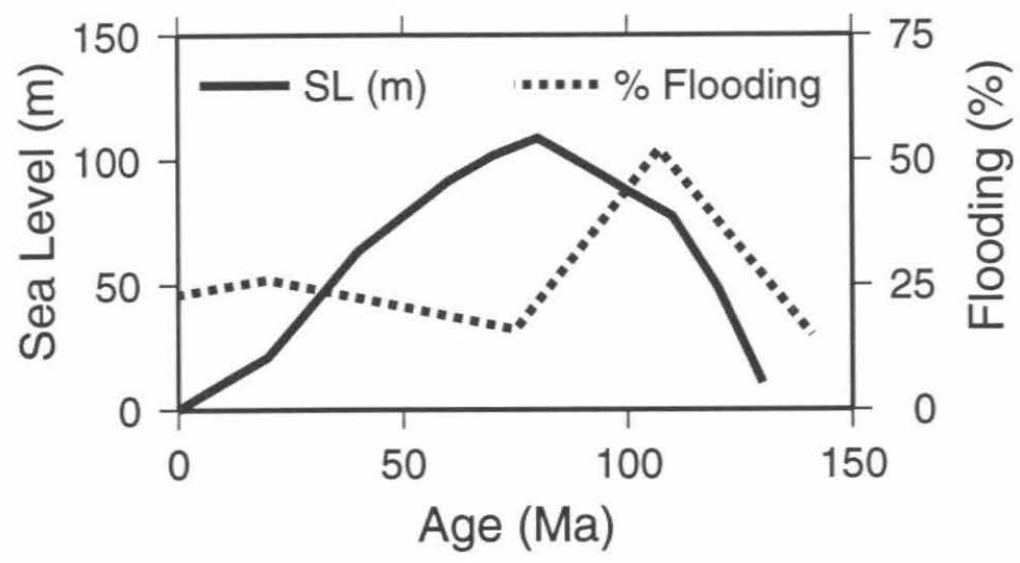

B. Vertical Motion

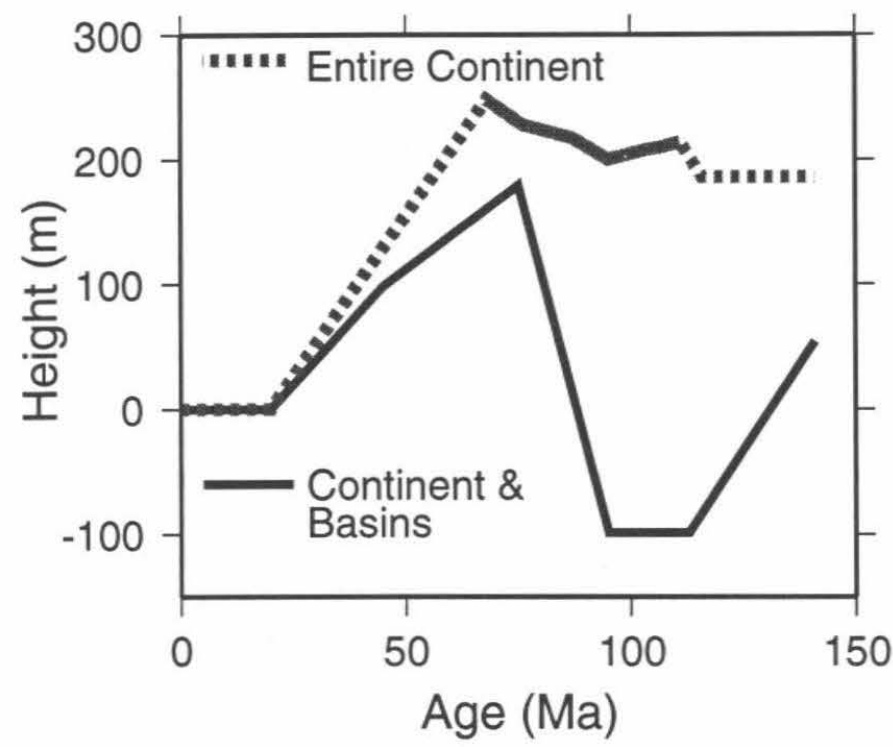

C. Observed Inundation

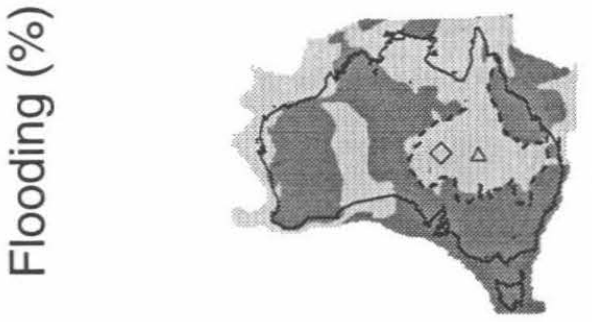

114-119 Ma

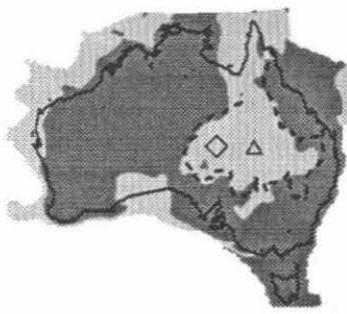

$104-110 \mathrm{Ma}$

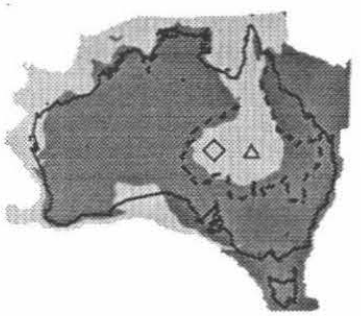

99-104 Ma

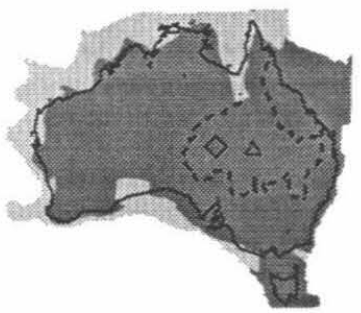

91-99 Ma

Figure 1. A. Eustatic, or global, sea level (solid line) inferred from passive margins in the Atlantic ocean [Watts and Steckler, 1979] and the percent area of Australia above $200 \mathrm{~m}$ below present sea-level flooded [Veevers, 1984]. B. Estimated vertical motion of Australia from hypsometric analysis. The motion of the entire continent, but excluding the eastern interior basins, is shown as the grey shaded line [Russell and Gurnis, 1994]. The vertical motion including the eastern basins is shown as the solid line (from Veevers [1984]). C. Paleogeographic reconstructions of Australia during the Cretaceous [BMR Paleogeographic Group, 1990]; light shading denotes marine inundation while medium shading denotes those parts of the continent that were subaerially exposed. Dashed line is the outline of the Eromanga and Surat basins and the Walkandi-1 [Gallagher and Lambeck, 1989] and Wareena-1 [Gallagher, 1990] boreholes are denoted with a diamond and triangle, respectively. 


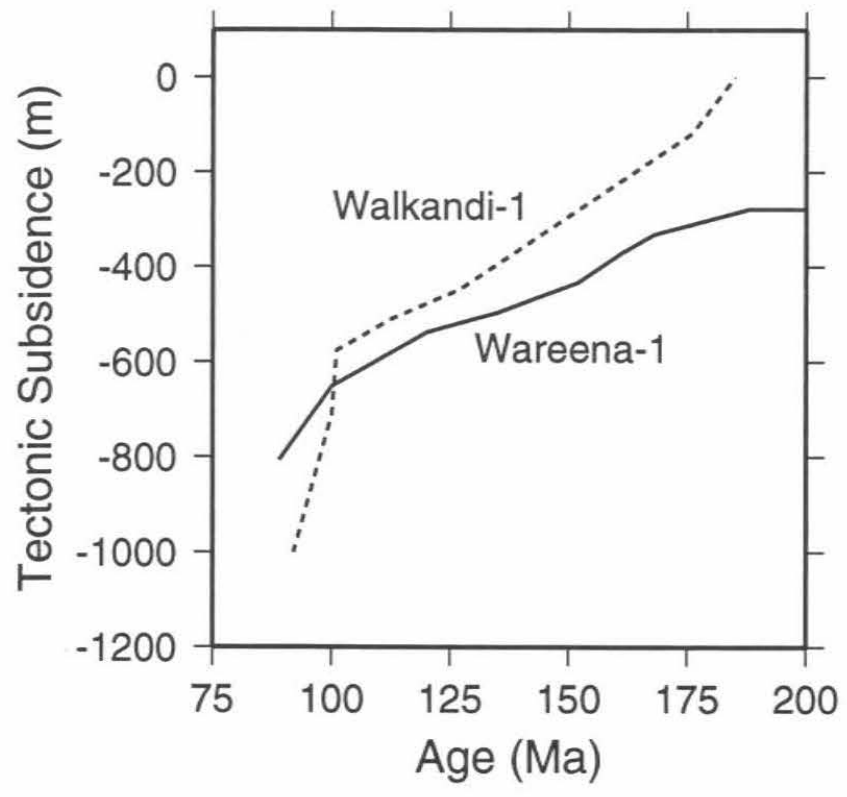

Figure 2. Tectonic subsidence for two boreholes within the Eromanga basin, the Walkandi-1 [Gallagher and Lambeck, 1989] and Wareena-1 [Gallagher, 1990]. Their positions are shown on Figure 1.

for the southern ocean here. Geographical variations in the isotopic composition of oceanic basalts is yet another powerful set of constraints which hitherto has not yet been quantitatively compared to physical models.

\subsection{Australian-Antarctica Discordance}

The Southeast Indian Ocean formed with oceanic spreading between Australia and Antarctica primarily since $45 \mathrm{Ma}$, although initial seafloor spreading dates to about $90 \mathrm{Ma}$ [Cande and Mutter, 1982]. The Australian-Antarctic Discordance (AAD) is an unusual segment of the Southeast Indian Ridge (SEIR) between $120^{\circ}$ and $128^{\circ} \mathrm{E}$, south of the Great Australian Bight (GAB). It is characterized by extremely rugged ridge flank morphology, axial depths $800 \mathrm{~m}$ deeper than normal, and a series of closely spaced, N-S trending fracture zones (Fig. 3A; Weissel and Hayes [1974]). The prevailing view since the work of Weissel and Hayes [1974] is that the AAD represents either a cold-spot or a cold down welling within the mantle but that this concept has often been difficult to grasp since ridges are thought of as regions of upwelling mantle.

The clearest means by which to view the AAD is through residual topography - the topography which results when the normal subsidence of the oceanic lithosphere is removed from observed bathymetry. The oceanic lithosphere is the simple conductive thermal boundary layer of mantle convection [e.g., Davies and Richards, 1992], and bathymetry increases as age $e^{1 / 2}$ where age is that since formation at the mid-oceanic ridge. We believe that the preponderance of evidence concerning the oceanic lithosphere is most consistent with it behaving as a cooling, semi-infinite half-space. However, because bathymetry tends to flatten for ages greater than $80 \mathrm{Ma}$, the half-space model is often not accepted and a so-called plate model is preferred (see discussion in Davies [1988]). Fortunately, the question of which model to use for the oceanic lithosphere is moot in this region because essentially all of the oceanic lithosphere between Australia and Antarctica has formed since $45 \mathrm{Ma}$ (Fig. 3B). Following Pribac [1991] bathymetry is corrected for conductive cooling using

$$
h_{r}=h_{o}-\left(2600+220 a^{1 / 2}\right)
$$

where $h_{r}$ is residual depth (in meters), $h_{o}$ is observed bathymetry, and $a$ is age of the oceanic lithosphere (in Myr). In addition, we correct for sediment loading using the procedure in Schroeder [1984]. When corrected for normal subsidence and sediment loading, the resulting residual depth is characterized by a prominent linear north-south trending depression from the GAB through to the AAD [Cochran and Talwani, 1977] and down to nearly the Antarctic margin with depths exceeding 1000 meters (Fig. 3C). Previously, it does not seem to have been widely recognized that the depth anomaly is nearly "V" shaped and symmetrical with respect to the SEIR. In comparison with global residual oceanic topography, the AAD is the most prominent, excessively deep, bathymetric anomaly not associated with present day subduction [Pribac, 1991]. The only other region with equally large residual depth is the East Philippine Sea which is controlled by both a thinner oceanic crust and dynamic topography from present day subduction [Gurnis, 1993]. The character of the SEIR depth anomaly has the appearance of a property (such as thinner crust) fixed with respect to the plates as they move slowly eastwardly with respect to a fixed point - much as a fixed hot spot gives rise to thicker crust which is symmetrical with respect to a spreading center. 


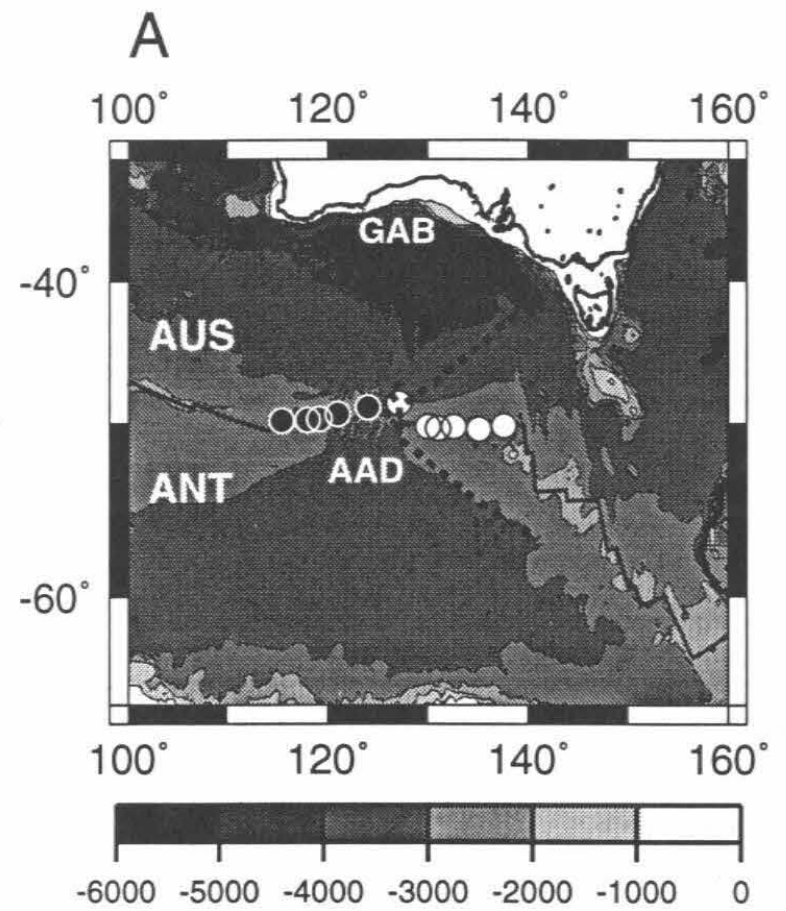

\section{Bathymetry $(\mathrm{m})$}

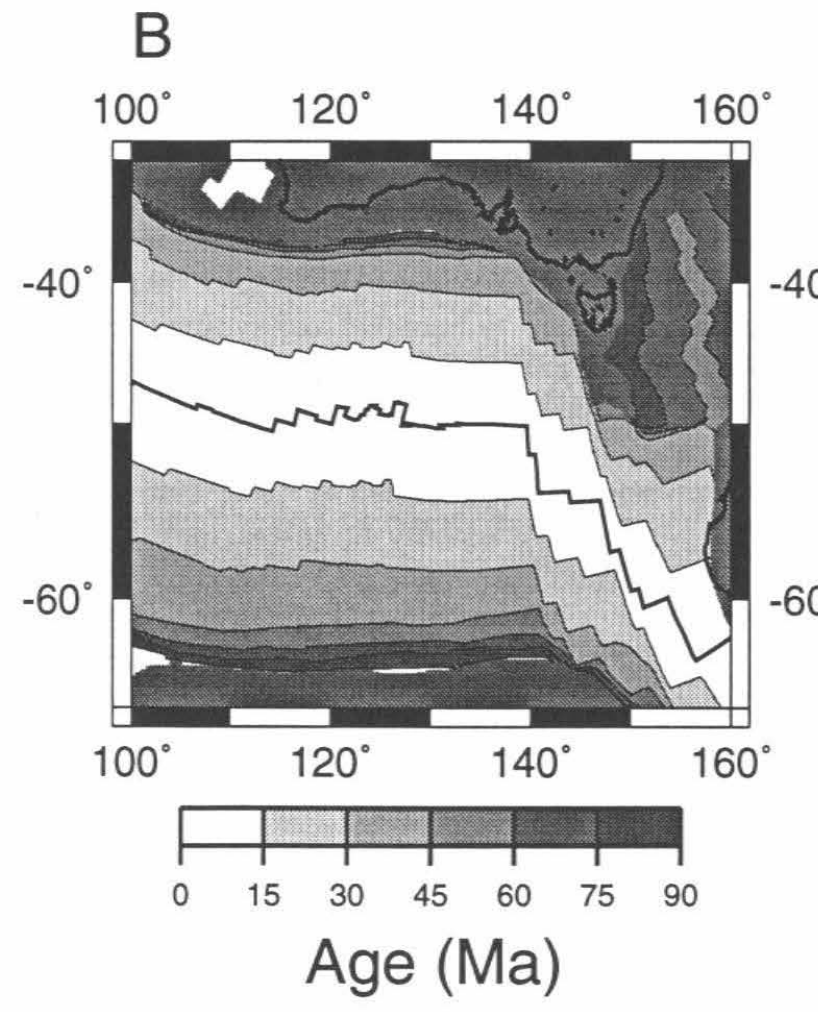

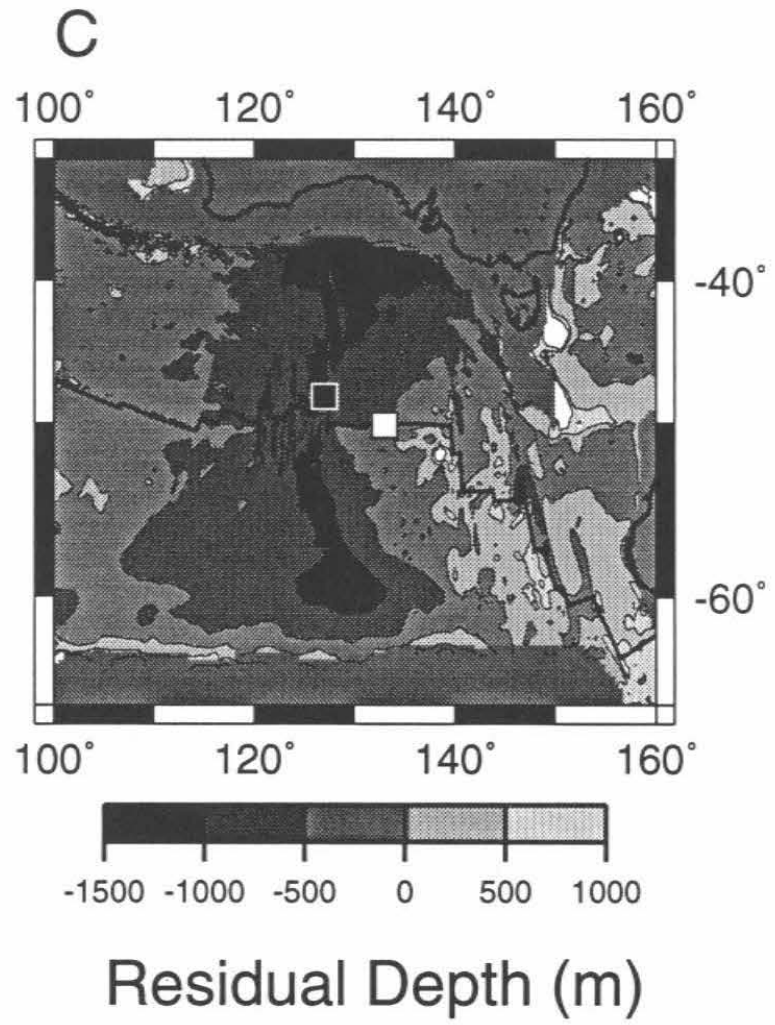

- Indian Ocean Isotopic Signature Pacific Ocean Isotopic Signature

Crustal Thickness $4.2 \mathrm{~km}$

Crustal Thickness $7.2 \mathrm{~km}$

Figure 3. Observed characteristics of the Southeast Indian Ocean. A. Observed bathymetry (ETOPO5) and isotopic signature of the mid-ocean ridge basalts [Klein et al., 1988]. B. Age of the ocean floor from Müller et al. [1997]. C. Residual topography (see text for details). Crustal thickness values from [Tolstoy et al., 1995]. 
There are different ways to distinguish between thinner crust and dynamic topography, including petrological models as a proxy for crustal thickness, direct measurement of thickness from seismology, and the gravity field. Major element systematics indicate that basalts making up the AAD are consistent with lower temperature mantle rising adiabatically under the ridge and crossing the solidus at lower pressure and experiencing a lower degree of melting [Klein and Langmuir, 1987]. As expected from the petrological model, the crust within the AAD has been measured from wide angle seismic refraction to be thinner than an adjacent part of the SEIR [Tolstoy et al., 1995], the AAD having a thickness of $4.2 \mathrm{~km}$ compared to the SEIR with a thickness of $7.2 \mathrm{~km}$ (Fig. 3C). The thermal anomaly responsible for the thinner crust can be estimated. Thermodynamic calculations and petrologic models show that oceanic crustal thickness increases as $0.06 \mathrm{~km}$ for each $1^{\circ} \mathrm{C}$ increase in mantle temperature [Langmuir et al., 1992; Asimov, 1997]. If we assume a difference of thickness of $3 \mathrm{~km}$ then a temperature difference of $50^{\circ} \mathrm{C}$ is implied. However, if we assume a difference between the AAD thickness and an average $6 \mathrm{~km}$ thickness of oceanic crust [McClain and Atallah, 1983] then only a $30^{\circ} \mathrm{C}$ anomaly is implied.

Assuming isostasy, it appears that less than half of the 1000 meter depth anomaly (Fig. 3C) can be accounted for by thinner crust. Using the observed difference in crustal thickness [Tolstoy et al., 1995] and a simple isostatic balance $\left(\rho_{c}=2900 \mathrm{~kg} \mathrm{~m}^{-3}\right.$ and $\rho_{m}=3250$ $\mathrm{kg} \mathrm{m}^{-3}$ ) a bathymetric difference of $470 \mathrm{~m}$ is predicted, significantly smaller than the observed $\sim 1000 \mathrm{~m}$. Using a more sophisticated isostatic balance and observed major element chemistry, Lecroart et al., 1997] predict a $400 \mathrm{~m}$ difference between observed and isostatic topography. Consequently, there may be comparable contributions to topography from both thinner oceanic crust and viscous stresses, e.g., dynamic topography, which arise from a cold and heavy mantle anomaly. This is the most reasonable interpretation of excess bathymetry. We suspect from the symmetry of the residual depth, which extends to at least $45 \mathrm{Ma}$ crust both north and south of the ridge, that the cold spot has been in existence for at least (and probably longer than) $45 \mathrm{Myr}$. Therefore, the portion of the mantle which is cold would be expected it to extend into the upper mantle a least a few hundred kilometers. If this truely reflects the structure deeper in the mantle, then it should contribute toward dynamic topography.

The existence of cold mantle beneath the AAD is corroborated by the along ridge distribution of isotopic variations. Along the $\mathrm{SEIR}, \mathrm{Sr}, \mathrm{Pb}$, and $\mathrm{Nd}$ isotopic systematics of basalts reveal that there are two distinct isotopic provinces: one to the west of the AAD characteristic of the Indian ocean and one to the east characteristic of the Pacific (Fig. 3A). These isotope systematics indicate long term $\left(10^{8}\right.$ to $10^{9} \mathrm{yr}$ enrichment and depletion of mantle reservoirs. The two provinces together are nearly globally encompassing [ Hart, 1984]. The isotope boundary is sharp but does become gradational on a scale of approximately $40 \mathrm{~km}$ [Pyle et al., 1992]. Klein et al. [1988] hypothesize that such a sharp isotopic boundary could be formed by down welling of material flowing east-west, parallel to the trend of the SEIR, toward the AAD. Relative down welling of the mantle is clearly consistent with the balance of the evidence which points toward cold mantle beneath the AAD. Further, Klein et al. [1988] hypothesize that the large-scale Indian Ocean isotope province [Hart, 1984] which comes to an abrupt termination at the AAD, could well be a remnant of the former Gondwanaland supercontinent with the isotope systematics consistent with sediment subduction, among other processes, beneath continental lithosphere [Klein et al., 1988; Pyle et al., 1992; Rehkamper and Hofmann, 1997].

\subsection{Seismic Structure of the Mantle in the Australian Region}

The shallow ( $<100 \mathrm{~km}$ depth) seismic structure of the Australian region is not particularly unusual (Fig. 4) - cratons are seismically fast and ridges and back-arc basins slow. Unfortunately, there are not large seismic sources in Antarctica which would provide crossing rays of the SEIR, so we rely upon the global Rayleigh wave inversion (Fig. 4) of van Heijst [1997]. Earlier, Forsyth et al. [1987] used a small number of relatively shallow and small events on the SEIR and inverted for 1-D structure from Rayleigh waves received in Australia for those paths which crossed the region with anomalously deep bathymetry and compared these to an inversion for paths which did not cross the anomalous region. They conclude that the mantle beneath the segment with deep bathymetry was characterized by unusually fast shear wave velocity in the depth range $20-40 \mathrm{~km}$. This is not inconsistent with the global inversion at 50 $\mathrm{km}$ depth where we see that the AAD segment is faster than the other ridge segments (Fig. 4).

A distinctive fast anomaly oriented N-S is evident directly beneath the AAD and becomes coherent at all depths $>500 \mathrm{~km}$ and extends down to at least $900 \mathrm{~km}$, the depth limit on resolution from the global model [ $v a n$ Heijst, 1997]. Inspection of the entire global inversion 
$50 \mathrm{~km}$

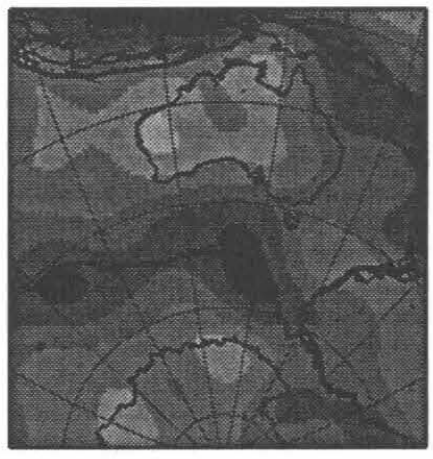

$300 \mathrm{~km}$

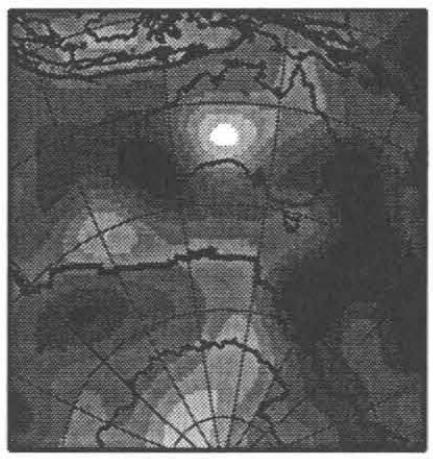

$700 \mathrm{~km}$

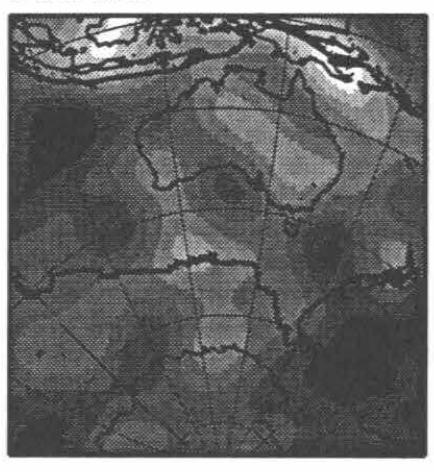

$900 \mathrm{~km}$

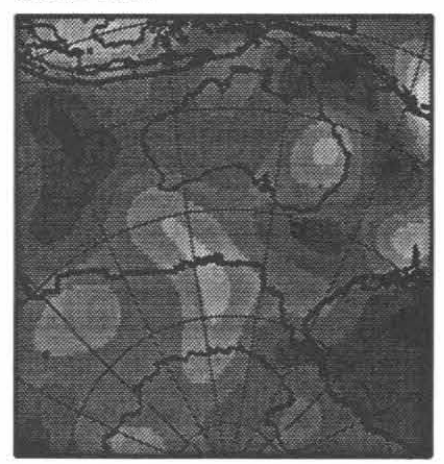

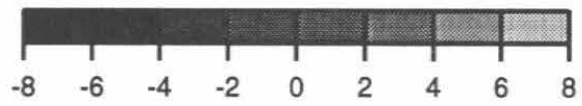

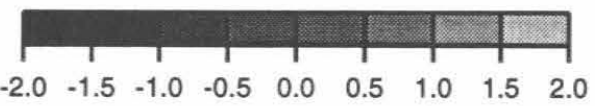

Figure 4. Shear velocity in percent from the global Rayleigh wave inversion of van der Heijst [1997]. The $8 \%$ scale is for $50 \mathrm{~km}$ and $100 \mathrm{~km}$ depths while the $2 \%$ scale is for all deeper levels. 
of the uppermost lower mantle shows that all substantial fast shear velocity anomalies are associated with Mesozoic to present subduction, as has been shown with body wave tomography [Grand et al., 1997]. Unfortunately, the global P- and S- wave models [Grand et al., 1997] have poor resolution in our study region through the upper mantle, but the resolution is better at the core mantle boundary and both P- and S- waves show a distinct seismic anomaly beneath the AAD. Most fast anomalies at the CMB are associated with Mesozoic subduction [Grand et al., 1997].

In summary, there is some indication of fast seismic velocity within the shallow upper mantle beneath the AAD, consistent with the lower temperatures inferred from the anomalous bathymetry, thinner crust, and petrological models. However, the most coherent anomaly beneath the AAD is an oblong, slab-like structure orientated N-S in the transition zone and lower mantle. Considering the association of all other lower mantle fast seismic anomalies with old subduction, we suggest that the sub-AAD anomaly could also be an old subducted slab.

\section{PLATE TECTONIC EVOLUTION OF THE AUSTRALIAN PLATE}

Throughout the Paleozoic and for much of the Mesozoic, the eastern Australian margin constituted a longlived active margin with a subduction zone located east of the Lord Howe Rise/Norfolk Ridge (Fig. 5A) [Symonds et al., 1996]. Widespread Triassic and middle Jurassic volcanogenic sediments in a foreland basin along the eastern Gondwanaland margin were derived from a magmatic arc along a west-dipping subduction zone [Jones and Veevers, 1983; Symonds et al., 1996]. The tectonic setting of the margin remained convergent until the Late Jurassic/Early Cretaceous, despite some local rifting events. The time of cessation of subduction has been subject of some controversy. The WhitsundayProserpine-Grahams Creek volcanic belt extending for about $900 \mathrm{~km}$ along the northeast Australian coast, are volcanic and intrusive intermediate to silicic, high- $\mathrm{K}$ calc-alkaline rocks, dated as 132-95 Ma [Ewart et al., 1992]. They had been interpreted by Veevers [1984] as andesitic, subduction-related volcanism. However, more recently, Ewart et al. [1992] and Bryan et al. [1997] have shown that their calc-alkaline signature is inherited from a crustal source, and that volcanism occurred in a low-relief extensional environment, with no evidence for a high-standing Andean-type magmatic arc. Therefore, it is now thought that subduction of the Phoenix Plate ceased off eastern Australia at about 130
Ma. Further south, in New Zealand, oblique subduction of the Phoenix Plate continued at least for another 20 Myr. Here, the earliest extensional tectonism is dated as 105-100 Ma [Laird, 1994], but is possibly as old as 110 Ma [Tulloch and Kimbrough, 1989]. Bradshaw [1991] suggested that the cessation of subduction was caused by subduction of the Phoenix-Pacific spreading ridge. As the slab that is now underlain the AAD corresponds to subduction off eastern Australia, we assume in our model that subduction ceased at $130 \mathrm{Ma}$.

The nature of the post-130 Ma plate boundary east of the Lord Howe Rise is not well known, but closure of the Pacific-Antarctic-Australian plate circuit back to about $86 \mathrm{Ma}$, including a preliminary model for relative motion between East and West Antarctica from $S$. C. Cande [pers. comm.], suggests that it was a strike-slip margin after $86 \mathrm{Ma}$ [Gaina, 1998]. The margin maintained its strike-slip character until about $43 \mathrm{Ma}$, when convergence between the Pacific Plate and the Australian Plate may have been reinitiated [Gaina, 1998].

\section{SET UP OF MANTLE CONVECTION MODELS WITH IMPOSED PLATE TECTONICS}

\subsection{Overview of formulation}

Mesozoic paleogeographic reconstructions showing subduction near the restored eastern Australian margin and the detection of a slab-like structure within the lower mantle beneath the AAD, the approximate former position of subduction in a fixed hotspot reference frame (Fig. 5B), leads us to advance the hypothesis that a subducted slab moved through the mantle over the last $130 \mathrm{Myr}$, resulting in the anomalous Cretaceous vertical motion of Australia and a cold zone centered at the AAD. We would like to test this slab hypothesis by making comparisons between the observed Cretaceous inundation of Australia and present day geochemical and geophysical observations within the Southeast Indian Ocean, on the one hand, and dynamic models, on the other. A 'mantle convection' problem has to be formulated so that models start with a subducted slab initially at a continental margin with evolving plates on the surface.

The problem we set up is similar to a traditional mantle convection model [e.g., McKenzie et al., 1974] in that the conservation equations are solved to determine velocity and stress throughout the domain with time-dependence simulated by interleaving the solution of the momentum and energy equations. However, by attempting to construct a model which is intended to be compared with observations, tectonic plates (following 

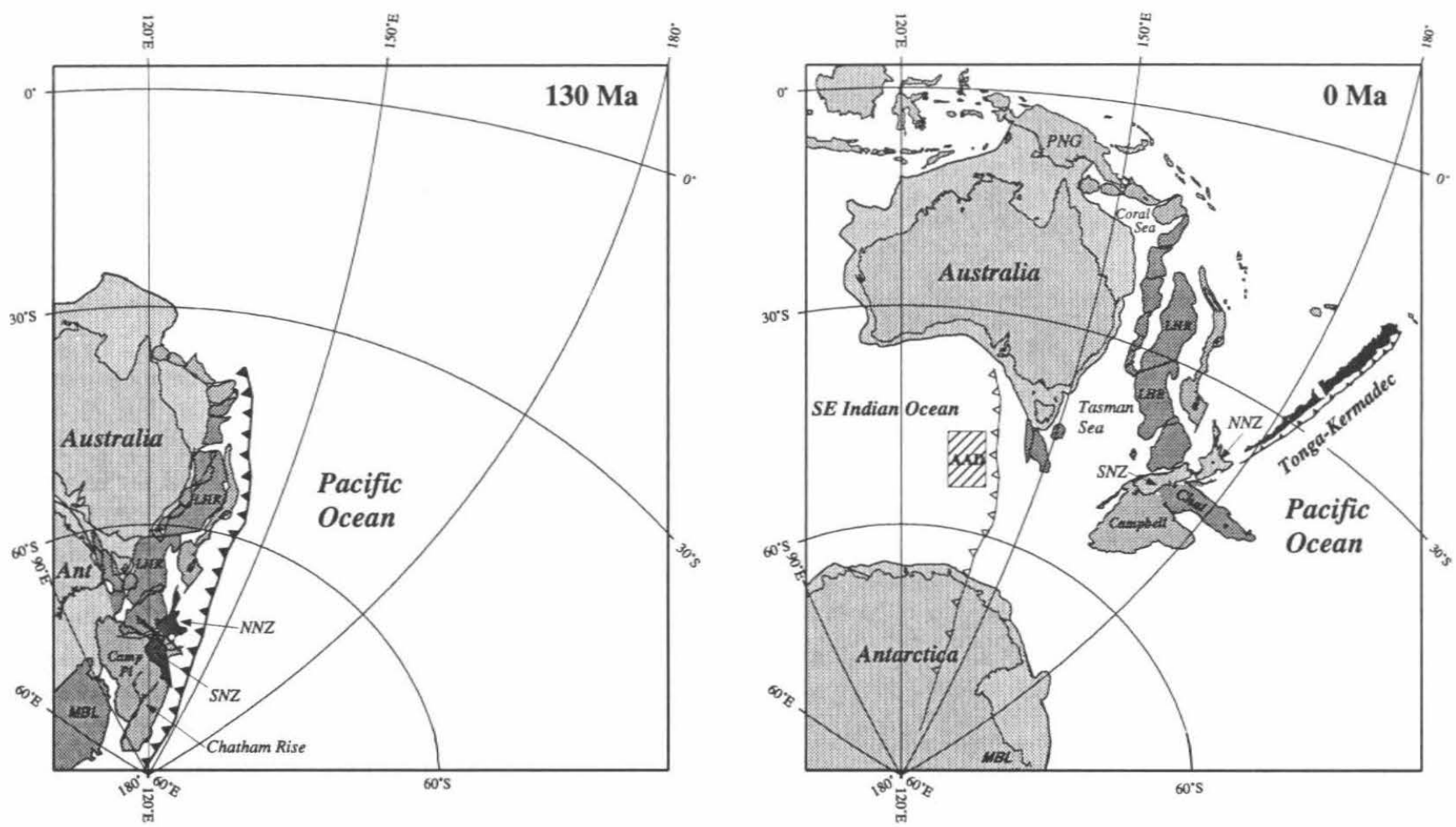

Figure 5. a. Reconstruction of Gondwanaland at $130 \mathrm{Ma}$ based on the absolute plate motion model relative to hotspots in the Atlantic-Indian oceans by Müller et al [1993], and relative plate motions from Gaina [1998] and Müller et al [1998]. Before this time, a westward dipping subduction zone was located east of the Lord Howe Rise (LHR), which became extinct at about $130 \mathrm{Ma}$. The projection is general sterographic, with the projection center at $120^{\circ} \mathrm{E}, 30^{\circ} \mathrm{S}$. b. Present-day plate configuration in the southwest Pacific Ocean, with the $130 \mathrm{Ma}$ location of the subduction zone superimposed, now situated just east of the AAD.

past inferred motions) must be incorporated. A selfconsistent dynamic formulation could have plate kinematics and evolving plate geometry as predictions. Although this has been attempted with evolving faults in two-dimensions [e.g., Zhong and Gurnis, 1995], it is computationally difficult in three dimensions and a good match with observed plate kinematics can not be guaranteed. A fully dynamic model capable of predicting absolute plate motions would need to include all the important slabs and plate boundaries together with poorly constrained time-dependent, plate boundary constitutive relations amplifying the errors in the region of interest. So as to avoid the difficulty of matching observed velocities with a fully dynamic model, time-dependent plate kinematics can be incorporated as boundary conditions. Models with velocity boundary conditions and evolving buoyancy have been formulated so that imposed plates neither speed up nor slow down the flow from what would normally be generated with a free-slip top surface [e.g., Davies, 1986]. Unfortunately, this methodology is potentially problematical because the kinematic boundary conditions amount to an external force which the Earth does not have. Since lithosphere freely slides by the hydrosphere, the Earth has a free-slip top surface and the top surface does no work on the system.

The imposed plate velocity method has been assessed by Han and Gurnis [1999]. Fully dynamic models of plate evolution were created using a fault methodology and a free-slip upper surface. Since both evolving plate geometry and plate velocity are outputs of the fully dynamic model, velocity from the dynamic model can be imposed on a kinematic model. Comparing often complex slab structure resulting from dynamic and kinematic models, Han and Gurnis [1999] found that internal structure was nearly identical for integration times up to nearly $100 \mathrm{Myr}$. The velocity boundary condition, however, often did an order of magnitude 
more work on the system than did the slab. This result should be viewed with respect to dynamic models where slabs always do most of the work on the fluid interior. In kinematic models, this additional work was dissipated within the lithosphere [Han and Gurnis, 1999]. Although the criticism made of the kinematic approach is valid (i.e. velocity boundary conditions do substantial work on the system), the BC does not incorrectly alter the evolution of internal buoyancy compared to a model having plates generated self-consistently. Clearly, the imposed velocity approach is ideal for the present study investigating the descent of a slab through the mantle when the evolution of plate motions are known.

Topography, present day and time-variable, is a primary observable. Crustal and lithospheric thickness variations and dynamic topography are all important sources of changing topography. Isostatic contributions are well known - dynamic topography generated by viscous flow in the mantle less so. From the reference frame of one plate, contributions to topography work differently. Crustal thickness variations are fixed with respect to plates, although a plate itself can undergo internal deformation (e.g. non plate-like characteristics). Topography generated by conductive cooling of oceanic lithosphere is also fixed with respect to plates, and is almost entirely determined by the age of the lithosphere.

Dynamic topography is not fixed with respect to plates, as plates move with respect to changing dynamic topography [Gurnis, 1990]. Like most fluid dynamic problems, our mantle convection models employ an Eulerian solution of the equations on a fixed mesh. Stratigraphic observations (like subsidence inferred at a single borehole) are fixed to plates moving with respect to the Eulerian mesh and in this case a Lagrangian reference frame is more appropriate. The topographic 'history' of points fixed with respect to plates can be found by following individual parcels of material within the flow as they are carried over a changing dynamic topography field by the background flow and boundary conditions. Using this procedure, we can immediately extract tectonic subsidence curves. For the pattern of marine flooding, a Lagrangian coordinate system attached to a continent is needed and a sediment model can then act on this grid of points. Such sediment models can be complex, involving not only sedimentation, but erosion and sediment transport [Burgess et al., 1997].

We have adopted a simplified approach to tracking topography due to lithospheric thickening. Since our interpretation of the geologic evolution of the eastern Australian margin has no active subduction from 130 to $50 \mathrm{Ma}$, the buoyancy created from diffusion across the top boundary will not be inserted into the mantle. This means that the diffusive thermal boundary layer of the mantle can be removed and this is accomplished by fixing the temperature at the top of the box to the average mantle temperature. However, we will make the upper $100 \mathrm{~km}$ of the mantle have a high effective viscosity because although it is not needed to enforce the plate motions, the vertical distribution of viscosity strongly modulates the topographic response from the underlying flow [Richards and Hager, 1984]. In making comparisons between computed model topography and observations, we subtracted the normal thermal subsidence of the oceanic lithosphere from the observed bathymetry (Section 3.1, Fig. 3).

Another influence on topography is crustal thickness variations. Within our modeled continents, only sedimentation changes crustal thickness. For the oceans, a synthetic lithosphere is created from the modeled margin between the Australian and Antarctic plates. Oceanic crust is created with a thickness depending on mantle temperature below the ridge using the relation between mantle temperature and crustal thickness from Langmuir et al. [1992] and Asimov [1997] described above. Crustal thickness is computed by sampling the temperature within a $200 \mathrm{~km}$ region beneath the ridge. A crustal thickness and chemistry were assigned to points on the Australian and Antarctic plates and subsequently moved according to the plate model. When we make comparisons with the residual bathymetry for the Southeast Indian Ocean described above, we will sum the dynamic topography and the isostatic topography resulting from crustal thickness variations. In both cases the topography will be comparable since the cooling oceanic lithosphere has been eliminated.

\subsection{Numerical solution of mantle convection}

Equations for momentum, mass, and energy conservation are solved to obtain the evolution of the system. The infinite Prandtl number approximation, which is appropriate for extremely viscous fluids, produces an equation of motion which has no inertial terms (usually called the Stokes' equation),

$$
\nabla \cdot \boldsymbol{\tau}-\nabla p=\left[\alpha\left(T-T_{0}\right)-\sum_{k} \Gamma_{k} \frac{\Delta \rho_{k}}{\rho_{0}}\right] g \rho_{0} \hat{\mathbf{z}}
$$

in which $p$ is the pressure, $g$ is gravitational acceleration, $\rho_{0}$ is the density at a reference temperature $T_{0}, T$ is temperature, $\Gamma_{k}$ and $\Delta \rho_{k}$ are the phase function (a marker which indicates the equilibrium phase at a given 
location) and density jump for the $k$ th phase change, and $\hat{\mathbf{z}}$ is a unit vector in the vertical direction. Across the $k$ th phase change, the phase function, $\Gamma_{k}$, increases by 1 . The deviatoric stress tensor is given by

$$
\tau_{i, j}=\frac{\eta}{2}\left(\partial u_{i} / \partial x_{j}+\partial u_{j} / \partial x_{i}\right)
$$

where $\eta$ is the dynamic viscosity, $u_{i}$ is a component of velocity, and $x_{i}$ is a component of the Cartesian coordinate system. For an incompressible fluid, the continuity equation becomes

$$
\nabla \cdot \mathbf{u}=0 .
$$

The energy equation is

$$
\frac{\partial T}{\partial t}=\kappa \nabla^{2} T-\mathbf{u} \cdot \nabla T+Q
$$

where $t$ is time, $\kappa$ is thermal diffusivity, and $Q$ is the volumetric heat production which is assumed to be zero for the present study.

The equations are non-dimensionalized such that with the boundary and initial conditions, the problem is determined by the following non-dimensional parameters.

$$
\begin{gathered}
R a=\frac{g \alpha \rho_{0} \Delta T D^{3}}{\kappa \eta_{u m}} \\
R_{k}=\frac{\Delta \rho_{k} g D^{3}}{\kappa \eta_{u m}} \\
\gamma_{k}^{\prime}=\frac{\gamma_{k} \Delta T}{\rho_{0} D g}
\end{gathered}
$$

where $R a$ is the thermal Rayleigh number, $R_{k}^{\prime}$ and $\gamma_{k}^{\prime}$ are the phase change Rayleigh number and normalized Clapeyron slope for the $k$ th phase change, $\eta_{u m}$ is the viscosity of the upper mantle, and $D$ is the depth of the box.

The dynamic viscosity, $\eta$, in (3) can be temperaturedependent. We use the following non-dimensionalized form of the Arrhenius relation [e.g., Ranalli, 1995]

$$
\eta=\eta_{m} e^{\frac{E^{\prime}}{T+T_{1}^{\prime}}}
$$

where $E^{\prime}$ and $T_{1}^{\prime}$ are non-dimensional free parameters and $\eta_{m}$ is the nominal viscosity of the lithosphere, upper mantle, and lower mantle (Table 2). $E^{\prime}$ can be approximately related to the activation energy, $E_{a}$.

The equation of motion (2) is elliptic and thus has properties which make special solution methods necessary for three dimensional problems. In particular, stresses are propagated instantaneously through the fluid such that at each time step the response to a local change in buoyancy is felt everywhere. The distributed response of the fluid to stresses makes explicit solution methods impracticably slow - it takes far too long for information to propagate back and forth across the numerical grid to reach equilibrium. Instead, the system of equations are solved implicitly by formulating a discrete representation on a grid and solving the resulting matrix equation. A number of discretization procedures are possible but the finite element method is used because it is robust in the face of discontinuous layering and strong variations in material properties.

The most robust way to solve the finite element matrix representation of (2) and (4) is a direct matrix solver which uses techniques such as Crout elimination [Hughes, 1987] optimized to take advantage of the sparse nature of the finite element matrices. The principal difficulty with this strategy is that with large scale problems (such as realistic 3D problems with many grid points), direct solution methods require a computational effort proportional to $N^{3}$ where $N$ is the number of unknowns. As $N$ becomes large, the solution time rapidly becomes unmanageable. Iterative methods, in which a series of approximate solutions converge on an accurate answer, are often more efficient for large problems but are usually less robust than direct solution methods. Conjugate gradient schemes, for instance, can solve a problem with $N$ unknowns in a time proportional to $N \log N$. The most efficient scheme is multigrid which uses a series of nested grids and can propagate information rapidly over all physical scales in the problem; its solution time scales, ideally, as $N$ [Press et al., 1992; Golub and Van Loan, 1989]. General iterative methods can be temperamental, particularly when strong variations in material properties occur between discretization points. The code we use, CITCOM, uses a multigrid solver which has been optimized in 2D and 3D for Stokes' flow problems in which the viscosity varies strongly across the grid [Moresi and Solomatov, 1995; Moresi and Gurnis, 1996].

The energy equation (5) is parabolic and requires different numerical treatment from the equation of motion. The diffusive term and the volumetric heat production term can be integrated in time from the initial condition without significant difficulty. However the advective transport term can pose greater difficulties because the advection of quantities on the mesh is not just a question of moving values from one node to the next. Inevitably, values from the middle of an element will be transported to a node during a timestep. This constitutes an interpolation, although it is not usually written out explicitly, and repeated interpolation does not preserve information. The result is an artificial diffusion 
Table 1. Summary of Controlling Parameters

\begin{tabular}{lcc}
\hline Parameter & Symbol & Value \\
\hline Depth of Box & $D$ & $2000 \mathrm{~km}$ \\
Acceleration of gravity & $g$ & $10 \mathrm{~m} \mathrm{~s}^{-2}$ \\
Coefficient of thermal expansion & $\alpha$ & $2 \times 10^{-5} \mathrm{~K}^{-1}$ \\
Temperature scale & $\Delta T$ & $1400 \mathrm{~K}$ \\
Ambient density & $\rho_{0}$ & $3300 \mathrm{~kg} \mathrm{~m}^{-3}$ \\
Thermal diffusivity & $\kappa$ & $10^{-6} \mathrm{~m}^{2} \mathrm{~s}^{-1}$ \\
Dynamic viscosity & $\eta_{u m}$ & $10^{21} \mathrm{~Pa}-\mathrm{s}$ \\
\hline
\end{tabular}

which tends to smooth the temperature field. There are a number of schemes designed to reduce this effect including Streamline-Upwind, Petrov-Galerkin [Brooks, 1981] which we use.

Dynamic topography was computed on the fixed mesh by assuming a balance between the vertical stress at the uppermost plane of nodes and the restoring force due to supposed deflections of the surface. We use the Consistent Boundary Flux (CBF) method [Zhong et al., 1993] which has been extensively benchmarked with both radial and lateral variations in viscosity [Moresi et al., 1996]. Solutions to the equations of motion do not change when a constant is added to the pressure. This in turn means that the dynamic topography has no absolute reference level so the output of the simulations always has the horizontal average of the topography removed. An alternative approach would be to assume a frame of reference associated with the sides of the box. There is only a small difference between these two approaches in the predicted subsidence and uplift associated with a falling slab. To ensure that no spurious topography signal is introduced by the imposed velocity boundary conditions, we compute surface stresses using the buoyancy field at any given time with a no-slip upper surface boundary condition.

\subsection{Application of the method to the Australian region}

The procedures described above can be used for many different convection problems, but to test the slab hypothesis we need to specifically tailor our regional Cartesian model. Plate kinematics, including plate margins, are transformed from a spherical surface to a Cartesian plane using an Azimuthal Lambert equal area projection. We used the continental outlines, isochrons and referenced rotations for relative plate motions from Müller et al. [1997] and absolute plate rotations based on hotspot tracks from Müller et al. [1993]. From 130 $\mathrm{Ma}$ to the present, the plate geometry is imposed as velocity boundary conditions which are updated every 10 Myr. All of the models are based on a box depth of 2000 $\mathrm{km}$ (Table 1); this depth is less than that of the whole
Table 2. Viscosity Model

\begin{tabular}{cc}
\hline Depth Range $(\mathrm{km})$ & Non-Dimensional Viscosity \\
\hline $0-100$ & 100 \\
$100-670$ & 1 \\
$670-2000$ & 100 \\
\hline
\end{tabular}

mantle, but has a volume greater than the mantle under an equivalent area of Earth's surface. We generally assumed a layered viscosity model (Table 2) which is consistent with the observed long-wavelength geoid associated with subduction zones [King, 1995]. Reflecting boundary conditions were used on all four side walls; on the base, we have used free-slip and isothermal conditions.

The initial condition of the subduction zone consists of a rectangular slab with a dip, $\theta_{s}$, an age, $\tau_{s}$, and a trench at a constant distance, $X_{s}$, from the left boundary of the box (Table 3). Having rotated the Lord Howe Rise back to its pre-rift position (Fig. 5a) our model trench was located parallel to the continental margin (Fig. 6). Clearly, this represents a simplification of the much more extensive Gondwanaland-Pacific margin, where convergence may have extended further toward New Guinea and certainly encompassed West Antarctica and South America. The subducted slab had a dip, $\theta_{s}$, through the upper mantle, but below $670 \mathrm{~km}$ the slabs were always vertical. This is consistent with active subduction shown by both seismic tomography [van der Hilst et al., 1997] and fully dynamic convection models with plates [Zhong and Gurnis, 1995].

A unique observation of this region is the abrupt change in isotope systematics along the SEIR. All hypotheses explaining the feature essentially have two large-scale geochemical reservoirs within the mantle meeting at the AAD. With our model formulation, we can test the hypothesis that an initially sharp boundary between two large-scale geochemical provinces, delineated by subduction before Gondwanaland breakup, caused the present boundary observed at the AAD. The two provinces contain passive tracers, i.e. neutrally buoyant so they do not influence the flow, inserted through the mantle with one group to the west (left) of the slab (Gondwanaland tracers) and the other to the right (east) of the slab (Pacific tracers).

The changing dynamic topography of this region evident from epeirogenic motion of Australia (Fig. 1B) is constrained by the pattern of marine inundation (Fig. $1 C)$. We model this inundation directly by using a simple model in which sediment accumulates at a constant rate for those points below sea-level. Because the model we formulate is regional, eustatic sea level 
Table 3. Summary of Mantle Convection Models

\begin{tabular}{|c|c|c|c|c|c|c|c|c|c|}
\hline \multirow[b]{2}{*}{ Case } & \multirow[b]{2}{*}{ Notes } & \multirow[b]{2}{*}{$\theta_{s}$} & \multirow[b]{2}{*}{$\tau_{s}(\mathrm{Ma})$} & \multirow[b]{2}{*}{$X_{s}$} & \multicolumn{2}{|c|}{$410 \mathrm{~km}$} & \multicolumn{2}{|c|}{$670 \mathrm{~km}$} & \multirow[b]{2}{*}{ Grid } \\
\hline & & & & & $\gamma^{\prime}$ & $R$ & $\gamma^{\prime}$ & $R$ & \\
\hline 1 & A34 & $30^{\circ}$ & 100 & 2.75 & 0.043 & 1.78 & -0.089 & 2.85 & $129 \times 65 \times 33$ \\
\hline 2 & A32 & $30^{\circ}$ & 100 & 2.75 & 0.043 & 1.78 & -0.089 & 2.85 & $65 \times 65 \times 33$ \\
\hline 3 & A26 & $30^{\circ}$ & 100 & 2.75 & 0.043 & 1.78 & -0.089 & 2.85 & $33 \times 65 \times 33$ \\
\hline $4^{5}$ & A31 & $30^{\circ}$ & 100 & 2.75 & 0.043 & 1.78 & -0.089 & 2.85 & $129 \times 65 \times 33$ \\
\hline 5 & A24 & $30^{\circ}$ & 100 & 2.75 & 0.000 & 1.78 & -0.089 & 2.85 & $33 \times 65 \times 33$ \\
\hline 6 & A 25 & $30^{\circ}$ & 100 & 2.75 & 0.085 & 1.78 & -0.089 & 2.85 & $33 \times 65 \times 33$ \\
\hline 7 & A 37 & $30^{\circ}$ & 100 & 2.75 & 0.000 & 1.78 & 0.000 & 2.85 & $65 \times 65 \times 33$ \\
\hline 8 & A35 & $90^{\circ}$ & 100 & 2.75 & 0.043 & 1.78 & -0.089 & 2.85 & $65 \times 65 \times 33$ \\
\hline 9 & A36 & $30^{\circ}$ & 100 & 3.25 & 0.043 & 1.78 & -0.089 & 2.85 & $65 \times 65 \times 33$ \\
\hline 10 & A 27 & $30^{\circ}$ & 50 & 2.75 & 0.043 & 1.78 & -0.089 & 2.85 & $33 \times 65 \times 33$ \\
\hline 11 & A28 & $30^{\circ}$ & 200 & 2.75 & 0.043 & 1.78 & -0.089 & 2.85 & $33 \times 65 \times 33$ \\
\hline $12^{\dagger}$ & A38 & $30^{\circ}$ & 100 & 2.75 & 0.043 & 1.78 & -0.089 & 2.85 & $65 \times 65 \times 33$ \\
\hline $13^{\ddagger}$ & A 32 & $30^{\circ}$ & 100 & 2.75 & 0.043 & 1.78 & -0.089 & 2.85 & $65 \times 65 \times 33$ \\
\hline
\end{tabular}

ๆ Temperature-dependent viscosity; $E^{\prime}=34, T_{1}^{\prime}=0.195$

${ }^{\dagger}$ No slab in lower mantle

$\ddagger$ Slab width in lower mantle $150 \mathrm{~km}$, half the value used in Cases 1-11

must be imposed. We use the global sea-level curve of Watts and Steckler [1979] which has been inferred from the stratigraphy of passive margins in the Atlantic, althought it is similar to other eustatic curves [Hallam, 1992]. Despite a general opinion to the contrary, in a dynamic planet spatial variations in sea level are much more strongly influenced by dynamic topography than the geoid [Gurnis, 1990; Lithgow-Bertelloni and Gurnis, 1997]. Consequently, we assume that at any given time the sea surface is 'flat' and tracks the eustatic change. For each point fixed to Australia sediment accumulates at a constant rate, $S$, between the solid and sea surfaces, a difference which is referred to as accommodation space. The sediment and water loads are isostatically compensated. We use sedimentation rates of $0-$ $20 \mathrm{~m} / \mathrm{Myr}$ which are consistent with the range observed for the north American platform during the Phanerozoic [Sloss, 1988]. The initial solid surface at $130 \mathrm{Ma}$ is modeled as either a constant height or has the shape of the present day topography but offset with a constant freeboard. We add dynamic topography at $130 \mathrm{Ma}$ and subsequently the surface height changes as sediment accumulates and dynamic topography changes.

\section{DYNAMIC MODELS: CRETACEOUS TO THE PRESENT}

We explore a variety of cases varying the uncertainties associated with the initial configuration of subduction $\left(\theta_{s}, \tau_{s}, X_{s}\right)$ as well as uncertainties intrinsic to the mantle (viscosity model, $\gamma_{k}^{\prime}, R_{k}$ ). In particular, we find that the results are sensitive to viscosity stratification through the transition zone and the strength of the phase transition at $670 \mathrm{~km}$ depth.

\subsection{Plate kinematics and topography}

We first consider a nominal model, Case 1, of a slab in which the trench is on average $1400 \mathrm{~km}$ east of the present coastline of Queensland (Fig. 6) and with an age of $100 \mathrm{Ma}$ and a dip of $30^{\circ}$. Case 1 has a Rayleigh number of $7.4 \times 10^{6}$ (based on upper mantle and transition zone viscosity of $10^{21} \mathrm{~Pa}$-s, and other parameters summarized in Table 1), no temperature-dependent viscosity and a factor 100 jump in viscosity at $670 \mathrm{~km}$ (i.e., viscosity model V2, Table 2). Using the values in Table 1, the dimensional Clapeyron slopes and density jump become $2.0 \mathrm{MPa} / \mathrm{K}$ and $5 \%$ at $410 \mathrm{~km}$ and -4.2 $\mathrm{MPa} / \mathrm{K}$ and $8 \%$ at $670 \mathrm{~km}$. In the marginal area off the coast there is a calculated prominent linear topographic depression (Fig. $6 \&$ 7A) which can be associated with an oceanic trench. The topography of this trough is significantly wider and shallower than oceanic trenches owing to the neglect of faulted plate margins which are required to reproduce the details of observed trenches; however, in the backarc region, there is little quantitative difference in dynamic topography between cases with and without faults [Zhong and Gurnis, 1996]. From $130 \mathrm{Ma}$ to the present, the slab descends under its own weight, is sheared by the shifting plates, and later partially drawn upward under a ridge.

We describe how the plate motions change over the course of the model; the plate motions are imposed as 

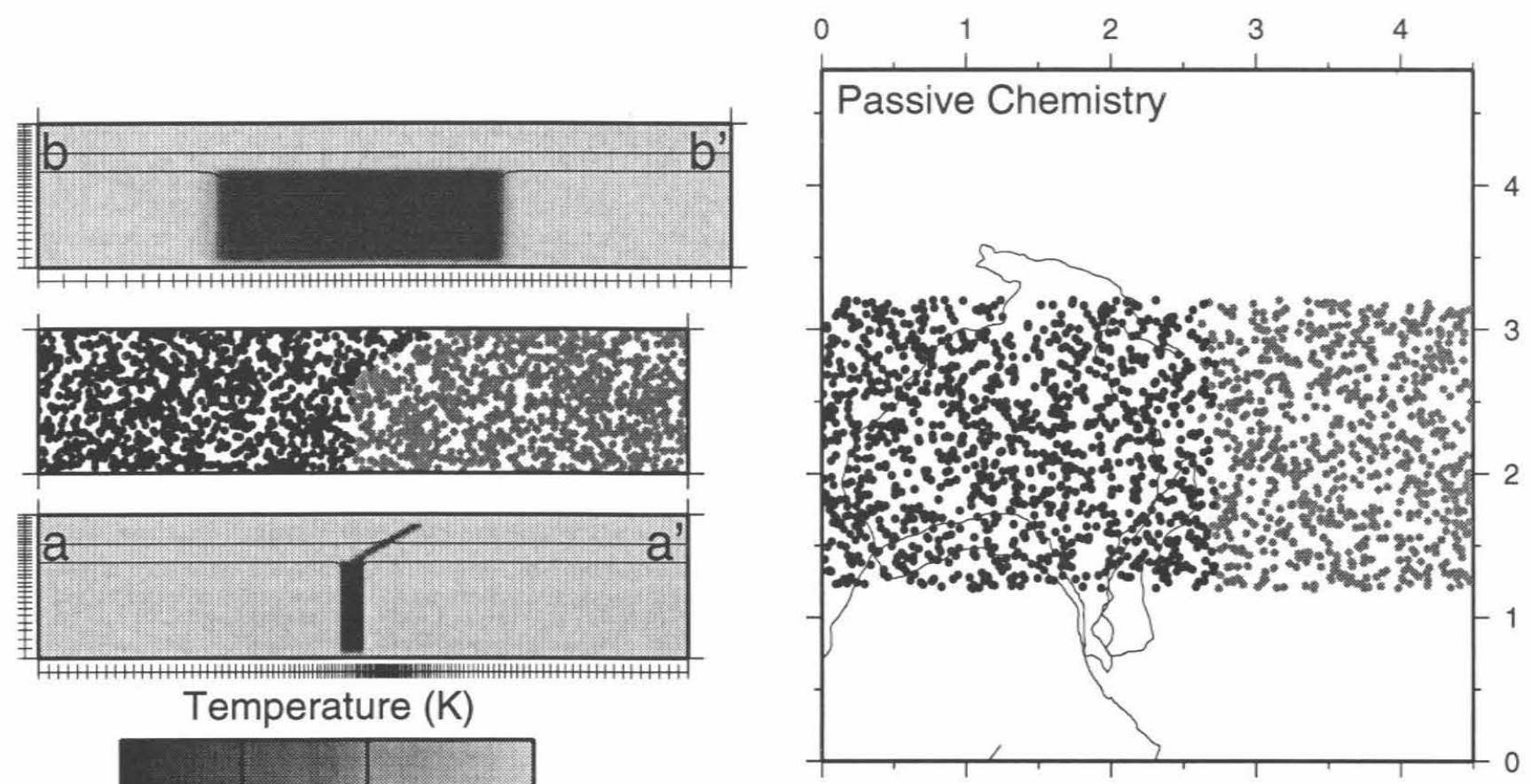

Temperature $(\mathrm{K})$
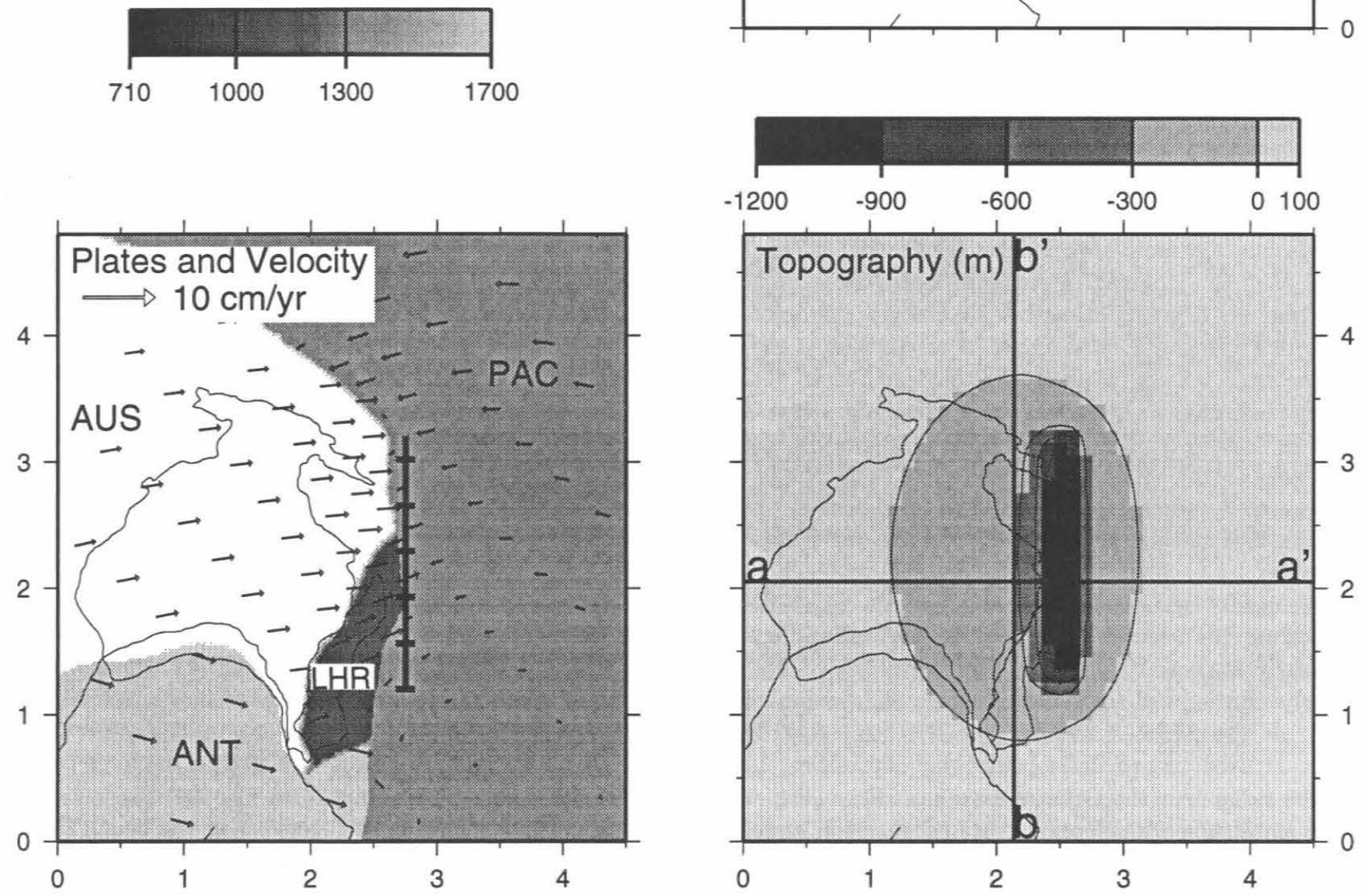

Figure 6. Initial condition for Case 1 with plate stencils (ANT for Antarctica, AUS for Australia, LHR Lord Howe Rise, and PAC for Pacific) and imposed velocity vectors shown on the lower left. The position of the trench is shown by the vertical line with the crossing tick marks such that the slab extends from $y=1.2$ to 3.2 . Major tick marks on the box edges have a $2000 \mathrm{~km}$ spacing. The domain is Cartesian with horizontal dimensions $4.5 \times 4.8$ and a depth of 1 . In the upper left, the initial configuration of the slab is shown by two intersecting cross-sections ( $a-a$ ' and b-b'); the center of the slab delineates the boundary between "Gondwanaland" tracers shown as black dots and "Pacific" tracers shown as grey dots. In the upper right, the tracers are plotted for those depths less than $10^{-5}$. 
boundary conditions, while the topography is predicted by the model. First, there is a general motion toward the Pacific (toward the right in the Cartesian model) by the three plates which are part of Gondwanaland (AUS, LHR, and ANT) with velocities exceeding $5 \mathrm{~cm} / \mathrm{yr}$ with respect to the hot spot reference (Fig. 7A - 7C). Second, following a period of relative quiescence (during which time Australia rifts from Antarctica but moves only slowly northward), Australia starts moving away from Antarctica at about $45 \mathrm{Ma}$ with nearly constant velocities between 7 and $8 \mathrm{~cm} / \mathrm{yr}$. While the plates change their positions, dynamic topography continuously evolves as the former slab changes its structure and depth distribution (Fig. 8A-D).

Inspection of the changing topographic signature as the imposed plate kinematics evolve reveals two fundamental features; these features are displayed by nearly all cases we explore and do not depend strongly on a range of plausible parameters, as described below. During the first phase of plate motion, Australia migrates over the topographic depression generated by the slab. From 120 to $110 \mathrm{Ma}$, the eastern interior of Australia is over the former position of subduction which is still a down welling (Fig. 8A) with up to $\sim 350$ meters of overlaying dynamic topography (Fig. 7B). There is a continued slow migration of the topographic depression westward over the continent while the amplitude of the topography decays; this means the continent, mostly in the east, uplifts by about $200 \mathrm{~m}$ from 110 to $60 \mathrm{Ma}$. The subsidence and uplift of the continent is shown well by the history of a point fixed to Australia. In Figure 9 (lower right) we show the changing dynamic topography, or tectonic subsidence, for the position of the Walkandi-1 borehole. From 130 to $120 \mathrm{Ma}$ this point subsides by $\sim 80 \mathrm{~m}$ but then from 100 to $90 \mathrm{Ma}$ this point uplifts by $\sim 100 \mathrm{~m}$.

During the second phase, while Australia starts in a nearly stationary position over a mild, $\sim-100 \mathrm{~m}$, nearly continental-scale topographic depression (Fig. 7D), as the SEIR starts to spread faster, a strongly concentrated, approximately circular depression, forms at the ridge near the Great Australian Bight (Fig. 7E). The amplitude of this concentrated depression increases from $45 \mathrm{Ma}$ onward and the increase in its magnitude accelerates over the last $20 \mathrm{Myr}$ (Fig. 7F).

During the first phase of westward motion, the slab, which initially has a $30^{\circ}$ dip (Fig. 6), partially stalls above the phase transition at $670 \mathrm{~km}$ depth (Fig. 8A). From $60 \mathrm{Ma}$ (Fig. 8B) to the present cold subducted material becomes drawn upward beneath the ridge (Fig.
$8 \mathrm{C}-\mathrm{D})$. At the present, the position of the ridge ( $\mathrm{R}$ in Fig. 8D) is directly above the area where mantle, a few tens of a degree cooler than normal, is being drawn upward. The intense circular topographic depression (Fig. $7 \mathrm{~F}$ ) is caused by a linear source of negative buoyancy orthogonal to the upwelling flow.

\subsection{Integration with sedimentation}

Dynamic topography changes for points fixed to plates because dynamic topography changes in time with respect to the box edges (comparable to a hot spot reference frame) and because the plates change their position. From this dynamic topography, we predict the marine inundation of Australia following the methods outlined in Section 5. The stratigraphic predictions are given as paleogeographic maps, inundation curves, borehole subsidence curves, and isopach maps (Fig. 9). The inundation of the continent is displayed as negative accommodation space.

For Case 1 with a sedimentation rate, $S$, of $5 \mathrm{~m} / \mathrm{Myr}$, we find that the eastern portion of Australia is flooded at $120 \mathrm{Ma}$ with a nearly uniform tilt downwards toward the east (Fig. 9). This marine inundation is directly related to the rapid eastward motion of Australia over the slab (Fig. 7A-B). From 120 to $100 \mathrm{Ma}$ the inundation becomes broad and migrates toward the west with decreasing accommodation spaces. By $90 \mathrm{Ma}$, however, only the Gulf of Carpentaria and smaller portions of the west (mostly the northern and southern margins in the west) are covered by a thin layer of water such that by $80 \mathrm{Ma}$ the continent has been nearly completely exposed, despite the increasing height of global sea level which peaks at $\sim 70 \mathrm{Ma}$ (Fig. 1A). From $80 \mathrm{Ma}$ to the present, the model continent remains completely exposed.

Given a dynamic topography prediction, the pattern of inundation is influenced by both the higher frequency component of topography due to crustal thickness variations and to sedimentation. As an end member case, we assumed the initial topography of Australia to be at a uniform $150 \mathrm{~m}$ height with respect to the ocean floor and from this the inundation was computed from simply adding the dynamic topography and eustatic sealevel change as a function of time (Fig. 10B). We see that a 'wave' of flooding spreads westward over Australia from 120 to $80 \mathrm{Ma}$. The inundation in this case is unlike that which was observed (Fig. 1C) - the observed flooding being confined much more to the east in 
A

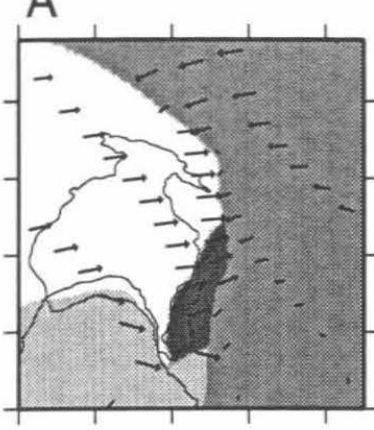

B
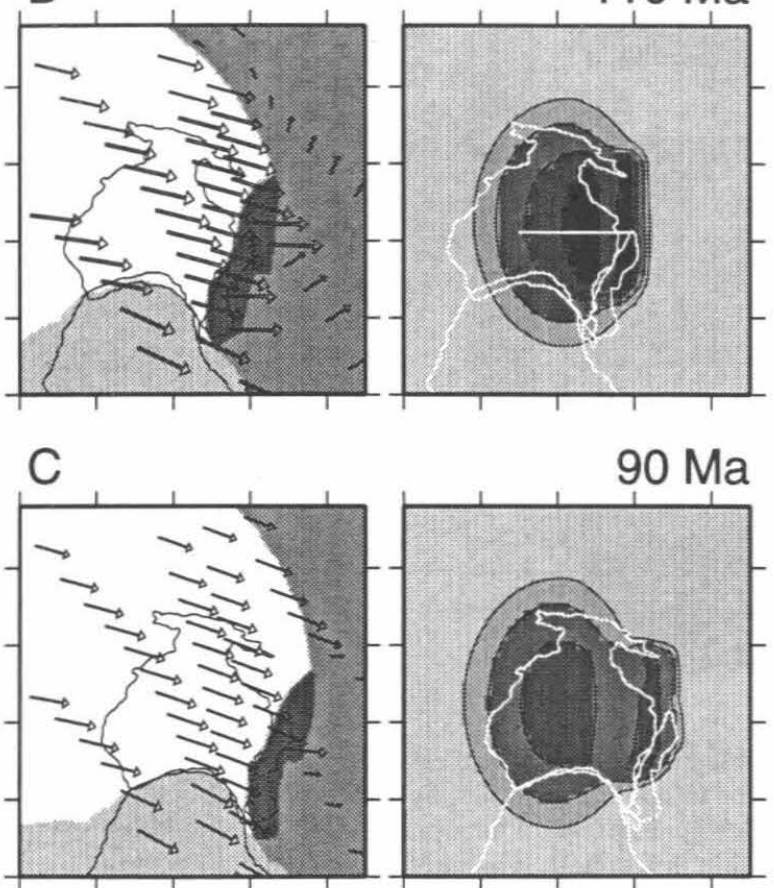

D

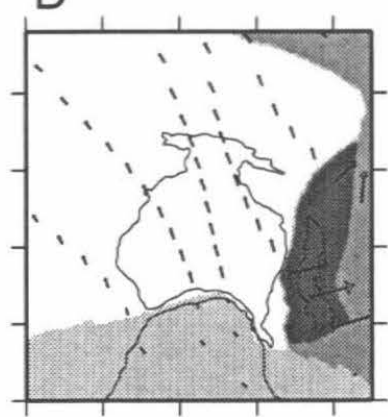

E
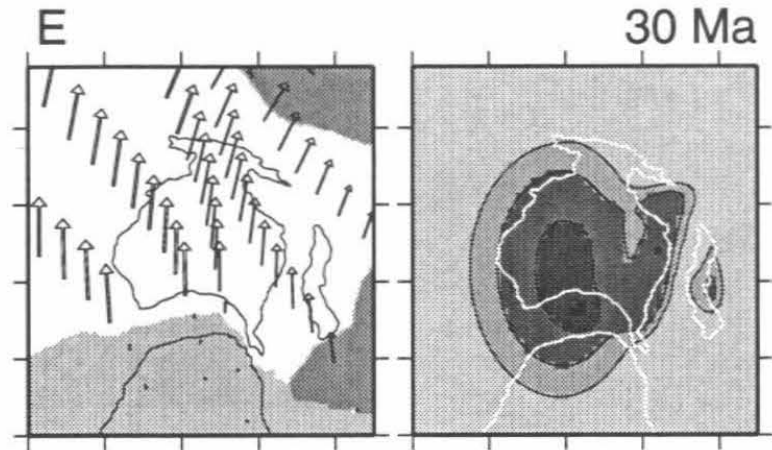

$\mathrm{F}$

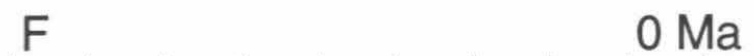

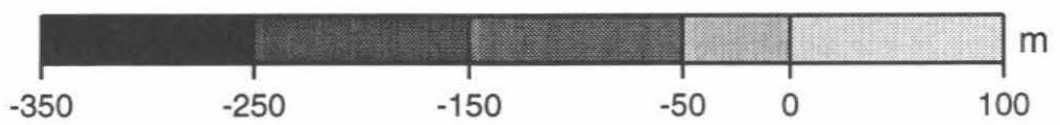

Figure 7. Plate stencils and imposed plate velocity (left) and predicted dynamic topography at six times for Case 1. The white lines on some of the topography plots denote the temperature cross sections shown in Fig. 8. At $130 \mathrm{Ma}$, the grey scale for topography is saturated; see Fig. 6 for the complete topography scale.

those areas which are presently topographically lowest. By increasing sedimentation rate from 5 to $10 \mathrm{~m} / \mathrm{Myr}$ (compare Fig. 10A with 10C), marine inundation becomes more confined to the east with earlier exposure of the continent during the sea level rise. In all cases, the continent becomes exposed because with sedimentation and an increasing sea level, there is uplift on a large-scale as dynamic topography decays.

\subsection{Present day geophysics and geochemistry}

With this dynamic model (Case 1) we predict the present day structure of oceanic lithosphere between Australia and Antarctica. Tracers and mantle temperatures are sampled beneath the ridge and moved with the two plates from $50 \mathrm{Ma}$ to the present at 10 Myr time intervals. On the modeled ridge an abrupt 


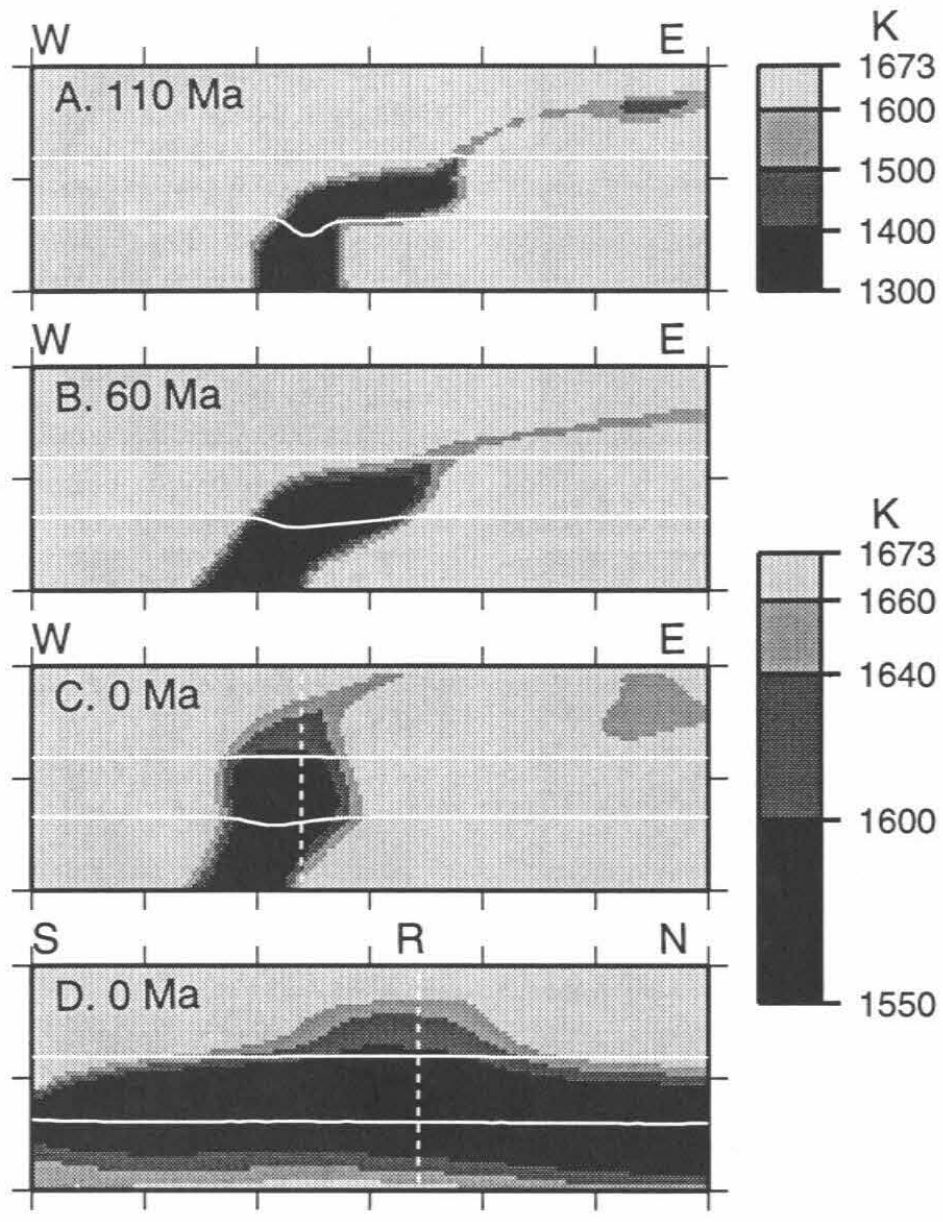

Figure 8. Vertical cross sections of temperature for standard model. A-C are nearly east-west profiles. $\mathrm{D}$ and $\mathrm{C}$ are two orthogonal sections with respective lines of intersection shown by white vertical dashed lines. Locations of cross sections are shown as white lines in Fig. 7. The upper scale is only for A (representing a large temperature span) while the lower scale is for B-D. The tick marks have a $500 \mathrm{~km}$ spacing. The horizontal white lines mark the positions of the $410 \mathrm{~km}$ and $670 \mathrm{~km}$ phase transitions.

change in chemistry is clearly evident as delineated by the sampled passive tracers (Fig. 11A) in close proximity to the depression in dynamic topography between $120^{\circ}$ and $130^{\circ} \mathrm{E}$. Moreover, the boundary between these two provinces has migrated to the west with an apparent velocity of $3-4 \mathrm{~cm} / \mathrm{yr}$, being partly a consequence of the $\sim 2 \mathrm{~cm} / \mathrm{yr}$ eastward component of Australian/Antarctic plate motion in the fixed hot-spot reference (Fig. 7F).

Two regions of thinner crust are evident (Fig. 11B) reflecting the sampling of cooler mantle. The two anomalies are oriented N-S but merge at $\sim 45 \mathrm{Ma}$ lithosphere. The anomaly to the east is due to the fragment of the slab which was sheared beneath the plates earlier in the computation. On Figure $8 \mathrm{~A}-\mathrm{C}$, notice the cool anomaly in the upper right. The more pronounced western anomaly is a $300 \mathrm{~km}$ wide region of thinned oceanic crust which develops at the ridge such that the center of thinned crust is essentially aligned with the distinct discontinuity in passive chemistry (Fig. 11B). The thinned crust does not extend uniformly northsouth from the ridge, rather, like the passive chemistry the thinned crust shows an apparent migration to the west. The thinning of the crust accelerates at about $20 \mathrm{Ma}$ from thicknesses only a few hundred meters less than normal $10 \mathrm{Myr}$ after rifting to over one kilometer presently. The thinned crust is caused by the drawing upward of a fraction of the old cold slab which had partially stagnated in the transition zone beneath the ridge (Fig. 8). The onset of significant thinning corresponds to the time it takes the slab to be drawn up from the transition zone (Fig. 8B-D) starting at 45 Ma when rifting between Australia and Antarctica accelerated (Fig. 7D-7E). Finally, both dynamic stress 


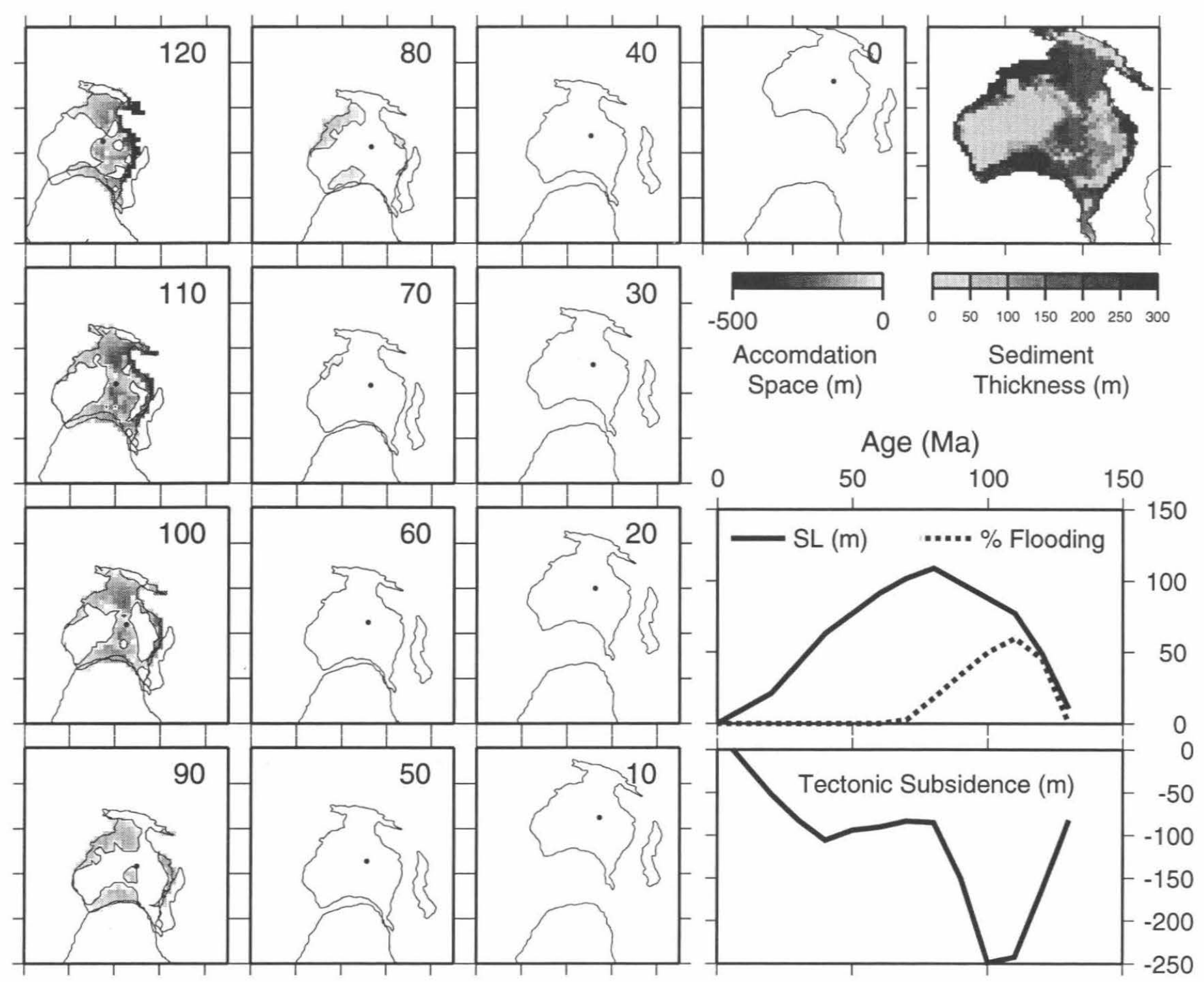

Figure 9. Maps (120 - $0 \mathrm{Ma}$ ) showing predicted marine inundation of Australia for Case 1 plotted as accommodation space with sedimentation rate of $5 \mathrm{~m} / \mathrm{Myr}$. Areas with gray scale spanning from light to dark are those areas covered by shallow seas; white regions denote those parts of the continent predicted to be exposed. In the upper right is predicted sediment thickness and in the lower right are the imposed eustatic sea level and predicted fractional inundation of the entire continent. Also shown is the tectonic subsidence for the Walkandi-1 borehole with the location shown as black dots in the maps, 120-0 Ma.

and thinner crust give rise to a distinct topographic depression, nearly $500 \mathrm{~m}$ in amplitude, on the ridge in the vicinity of $125^{\circ} \mathrm{E}$ (Fig. 11C).

\subsection{Influence of mantle rheology and phase transitions}

The predictions of the vertical motion of Australia and the character of the sea-floor between Australia and
Antarctica are sensitive to assumed mantle characteristics. We vary the temperature-dependence and radial variation of viscosity, and strength of phase transitions at $410 \mathrm{~km}$ and $670 \mathrm{~km}$ depth.

Silicate rheology is strongly thermally activated [e.g., Ranalli, 1995], so that the use of a constant lateral viscosity may appear to be a limitation of the nominal model. However, it is unlikely that slabs are as strong as predicted by a simple thermally activated rheology. 

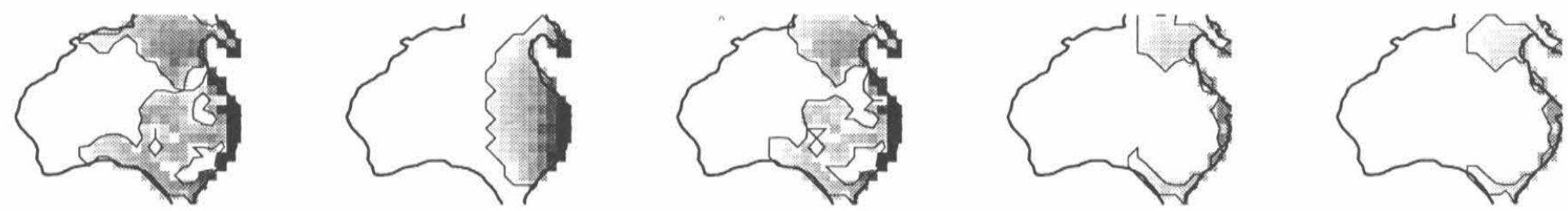

$120 \mathrm{Ma}$
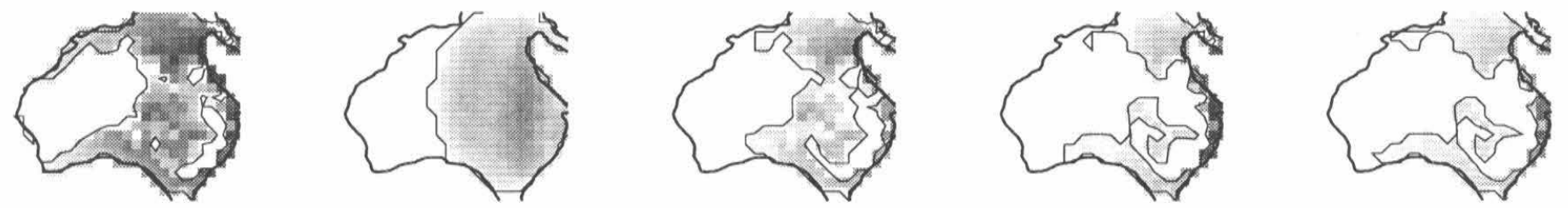

$110 \mathrm{Ma}$
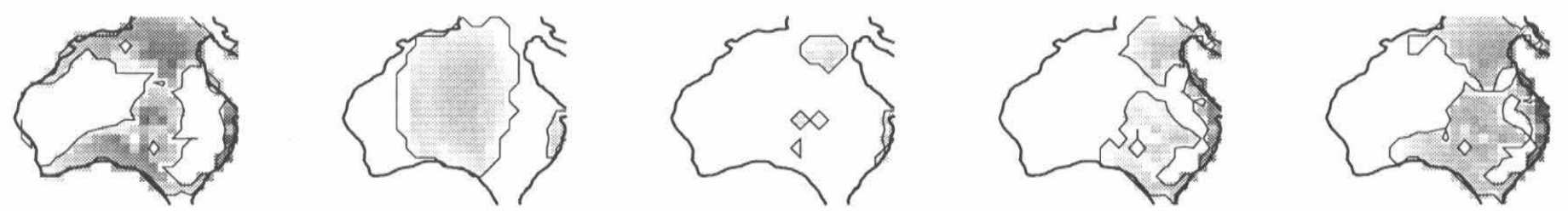

$100 \mathrm{Ma}$
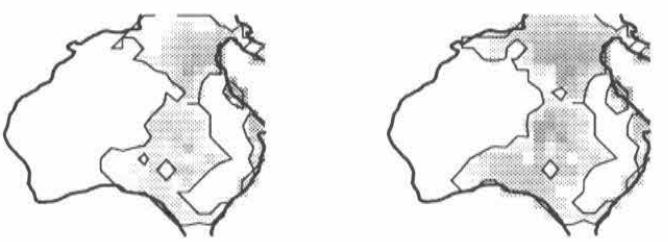

$90 \mathrm{Ma}$
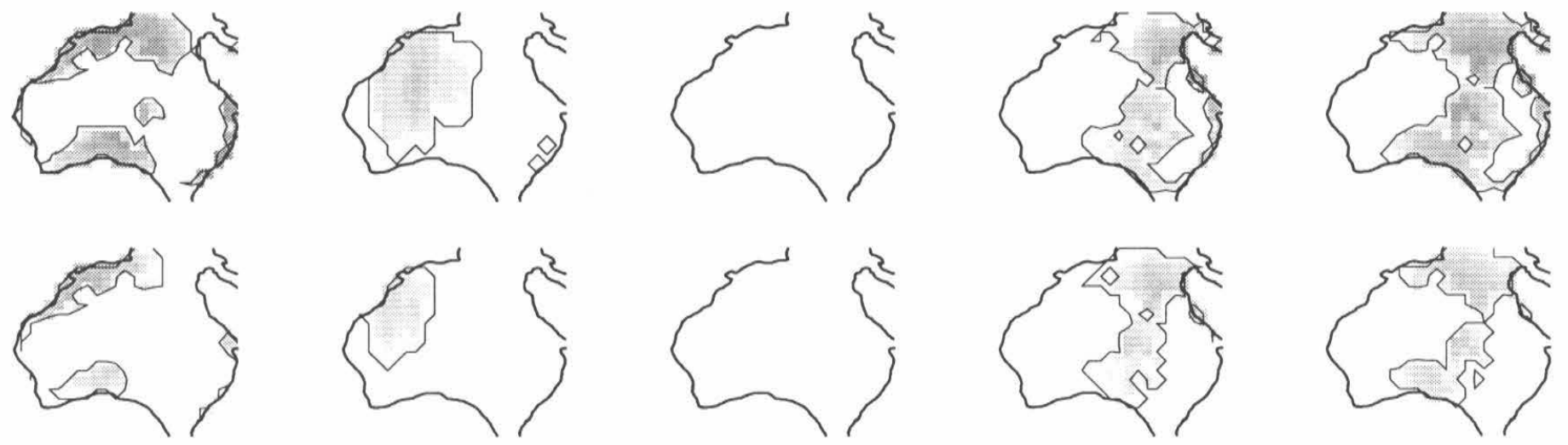

$80 \mathrm{Ma}$
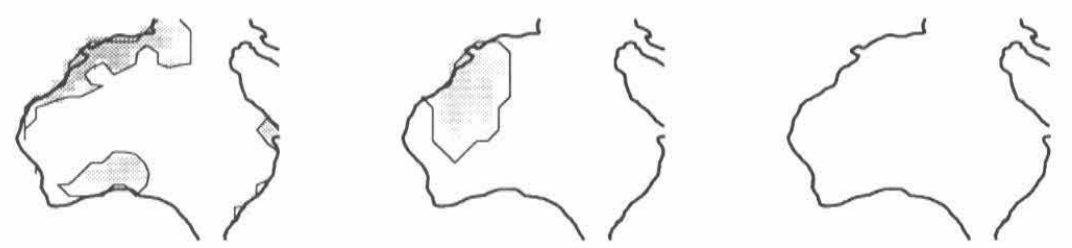

Accomodation Space (m)

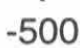

0

Figure 10. Predicted pattern of marine inundation for Australia from $120 \mathrm{Ma}$ to $80 \mathrm{Ma}$ in terms of accommodation space. A. Case $1 S=5 \mathrm{~m} / \mathrm{Myr}$. B. Case $1, S=5 \mathrm{~m} / \mathrm{Myr}$ but with an initially flat surface. C. Case $1, S=10 \mathrm{~m} / \mathrm{Myr}$. D. Case 8 with $\theta_{s}=90^{\circ}$ and $S=5 \mathrm{~m} / \mathrm{Myr}$. E. Case 9 with $X_{s}=3.25$ and $S=5 \mathrm{~m} / \mathrm{Myr}$. 

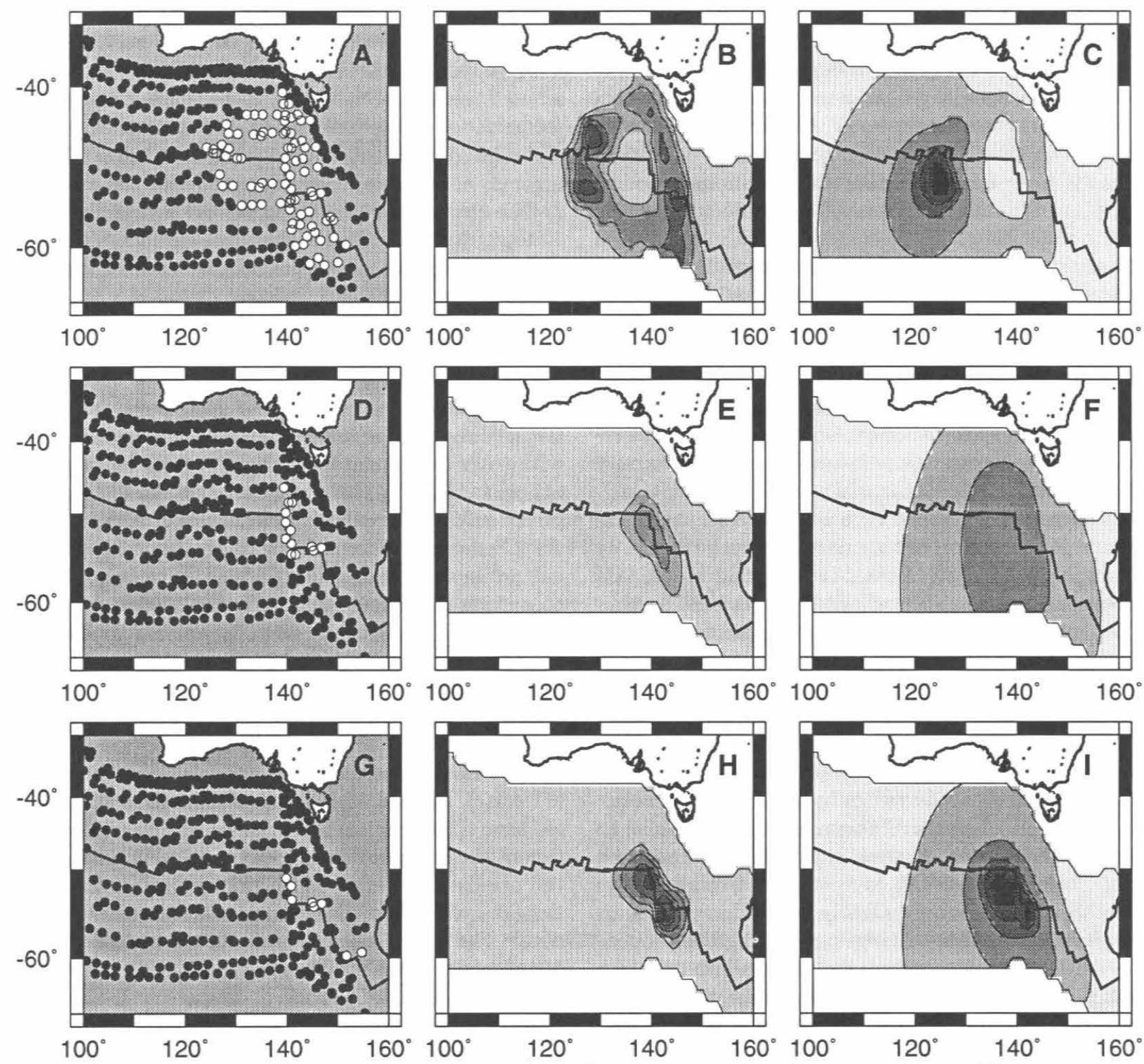

- Gondwanaland Tracers

- Pacific Tracers
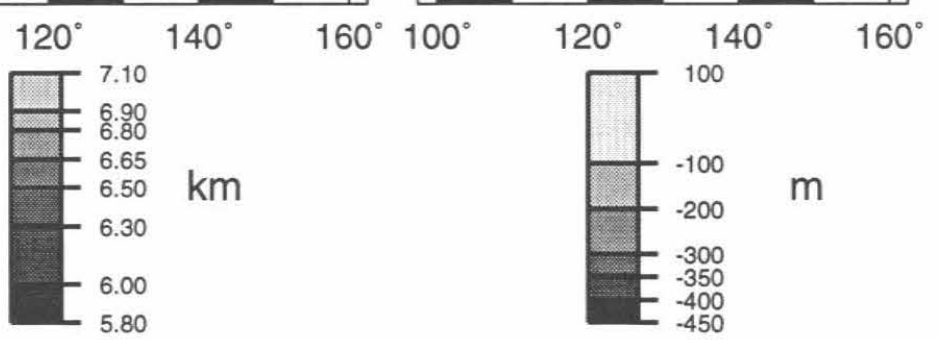

Figure 11. A-C. Predictions from Case 1. A. Tracers sampled at the ridge and rotated to present positions. B. Inferred crustal thickness based on mantle temperature. C. Total topography on the top surface driven by both viscous flow and crustal thickness. D-F. Same quantities for a identical model except for an initial vertically dipping slab, Case 8 . G-I Same quantities except for a $30^{\circ}$ dipping slab at $X_{s}=3.25$ for Case 9 . 
Theoretically, non-linear viscosity is expected to limit the variation induced by temperature-dependent viscosity [Christensen, 1984]. Moreover, strong slabs tend to give long wavelength geoid lows over slabs, not geoid highs as observed [Moresi and Gurnis, 1996]. With a model which incorporated a temperature-dependent viscosity, Case 4 , we find that the results become less realistic. With $E^{\prime}=34$ and $T_{1}^{\prime}=0.195$ in equation (9) the dimensional $E_{a}$ becomes $400 \mathrm{~kJ} / \mathrm{mol}$. Within a given layer, the maximum lateral variations in viscosity (e.g., viscosity of slab to background viscosity) are limited to 100 . Slab descent diminishes to only a few $\mathrm{mm} / \mathrm{yr}$ in the upper mantle and stagnates within the lower mantle because the slab base cannot deform and bend at the bottom boundary - not unlike the stagnation of the top thermal boundary layer in thermal convection with temperature-dependent viscosity [Christensen, 1984]. The magnitude of dynamic topography increased by about $20 \%$ compared to the nominal case for all times, but more importantly the decay of dynamic topography from $120 \mathrm{Ma}$ to $60 \mathrm{Ma}$ and its subsequent reappearance when Australia and Antarctic separated is not nearly as pronounced with strong as compared to weak slabs. Dynamic topography is significantly less time-dependent as strong slabs resist deformation.

The influence of the phase change at $410 \mathrm{~km}$ is minor. When the $410 \mathrm{~km}$ phase change is eliminated (Case 5), dynamic topography decreases by $20 \%$ from the nominal model and when the Clapeyron slope is doubled to $4.0 \mathrm{MPa} / \mathrm{K}$ (Case 6), dynamic topography increases by $25 \%$. However, after $130 \mathrm{Myr}$ of plate evolution, dynamic topography is only slightly reduced in cases with stronger $410 \mathrm{~km}$ phase changes, reflecting the propensity of the phase change to draw the slab into the transition zone and then subsequently to resist the drawing upward of cold fluid by the diverging plates. However, in no case are any of the major conclusions drawn from the nominal model changed with moderately larger or smaller Clapeyron slopes at $410 \mathrm{~km}$ depth.

The influence of the phase change and viscosity jump at $670 \mathrm{~km}$ are substantial. Holding the viscosity contrast between the upper and lower mantle constant and eliminating both phase transitions (Case 7), we find that it is no longer possible to trap a significant fraction of the slab above $670 \mathrm{~km}$ depth for significant time periods compared to a case with both phase changes present. The trapping of the slab by positive buoyancy of the phase change at $670 \mathrm{~km}$ depth, especially when the slab is sheared out by the eastward motion of Gondwanaland from $130 \mathrm{Ma}$ to $90 \mathrm{Ma}$ (e.g. Fig.
8A, Fig. 7A-7C) plays a fundamental role in the appearance of a distinct topographic depression and thin crust along an isolated part of the SEIR. The elimination of the phase change at $670 \mathrm{~km}$ has only a minor influence on the initial flooding of Australia from 120 to $80 \mathrm{Ma}$ and its subsequent exposure at $\sim 70 \mathrm{Ma}$, but strongly influences predictions made for the Southeast Indian Ocean. We are able to predict a mild undulation in topography, but are unable to reproduce the thinner crust near $130^{\circ} \mathrm{E}$.

\subsection{Influence of initial conditions}

The sensitivity of model outcomes which results from uncertainty in Jurassic paleogeography is explored by varying the initial value of the following: position of trench, initial dip angle of the slab, amount of slab within the lower mantle, and age of subducting lithosphere. Changing the characteristics of the slab has a direct influence on the inundation of Australia during the Cretaceous. Increasing slab dip from $30^{\circ}$ to vertical, while maintaining the position of trench (Case 8), or moving the trench an additional $1,000 \mathrm{~km}$ from the Australian margin while keeping slab dip fixed (Case 9), delays the time of inundation, as shown in Fig. 10D and $10 \mathrm{E}$, respectively. In both cases maximum flooding occurs at $100-90 \mathrm{Ma}$ and flooding persists past 80 Ma (Fig. 10D-E). The prolonged flooding in the eastern interior is inconsistent with observed inundation (Fig. 1C). In addition, these two paleogeographic models have a substantial influence on the predicted position of the topographic and geochemical anomaly along the present day ridge. With the vertical dipping slab, Case 8, little of the upper mantle slab becomes trapped within the transition zone, despite the strong shearing of the upper mantle by the fast eastward motion from $120-100 \mathrm{Ma}$ (Fig. 7C). Consequently, there is only an insignificant amount of cool mantle remaining within the upper mantle and transition zone when Australia moves away from Antarctica at $45 \mathrm{Ma}$ such that the predicted crustal thickness and depth anomalies are insignificant (Fig. 11E-F). Moreover, the anomaly is shifted approximately $2,000 \mathrm{~km}$ to the east in comparison to the case with the dipping slab. The model in which the initial trench is about $\sim 2,400 \mathrm{~km}$ from Queensland in the Jurassic also predicts a geophysical anomaly along the SEIR which is substantially displaced to the east (Fig. $11 \mathrm{H}-\mathrm{I})$.

The model with an initial vertically dipping slab shows little apparent westward migration of the geochemical anomaly (Fig. 11D) in comparison to the model with an initial $30^{\circ}$ dipping slab (Fig. 11A). This 
helps to explain why the apparent migration in Case 1 (Fig. 11A) is larger than the overall $2 \mathrm{~cm} / \mathrm{yr}$ eastward motion of the Australian and Antarctic plates. Part of the migration is the result of initial conditions - as the tracers are extracted from deeper depths as time progresses, the boundary between Gondwanna and Pacific tracers shifts to the west (Fig. 6).

We find that decreasing slab age from 100 to $50 \mathrm{Ma}$ has little influence because with the reduced negative buoyancy of the slab the rate of its descent decreases (Case 10). Although the slab has less negative buoyancy, the source is closer to the surface and the net change on dynamic topography is small. During the final 20 Myrs of the model, when cold material is drawn up by the ridge, fluid then present within the transition zone has a smaller temperature difference but it is drawn up more effectively. Consequently, the age of the slab has little influence on our conclusions. Finally, the initial amount of slab in the lower mantle is uncertain, but has a substantial influence on our predictions. With only an upper mantle slab (i.e. without slab extension into the lower mantle, Case 12), we find a strong influence on the characteristics of the present day ridge. None of the slab is pulled into the lower mantle so that a much larger fraction of the fluid remains to both decrease the temperature beneath the ridge and dynamically pull the topography downward. Crustal thickness and topography variations substantially increase with smaller amounts of lower mantle buoyancy (Case 12, 13).

\section{DISCUSSION AND CONCLUSIONS}

We have carried out a series of dynamic models with imposed plate tectonics and evaluated the hypothesis that both the anomalous marine inundation of Australia during the Cretaceous and the existence of a cold zone beneath the AAD are related to an ancient subducted slab. From our extensive modeling, we conclude that Australia first over rode this slab in the Cretaceous, but later the slab stagnated in the transition zone before being drawn upward over the last $20 \mathrm{Myr}$ by the SEIR. Predictions from dynamic models match observed quantities.

For a range of reasonable values, we are able to match observed inundation of Australia (Fig. 1A) with simple dynamic models of convection with imposed plate tectonics (Fig. 9). The uplift of Australia is a natural consequence of dynamic topography which decreases with the demise of subduction on the Pacific margin of Australia during the Cretaceous. A similar conceptual model has previously been proposed by Gallagher et al.
[1994] to explain thermal and sedimentary histories of eastern Australian basins. With both the stratigraphic constraints and the predicted character of the AAD, we reject two alternative paleogeographic reconstructions - one with a vertically dipping slab and the other with the trench $\approx 2,400 \mathrm{~km}$ from the Cretaceous margin. Our preferred model has the slab within about $1,500 \mathrm{~km}$ of the restored coast of Queensland in the Jurassic and dipping at a moderate angle.

The most significant limitation of the present models is the inability to explain the permanent subsidence of the Eromanga and Surat basins. Qualitatively, we judge from previous work [Gallagher et al., 1994; Russell and Gurnis, 1994] that about half of the Cretaceous subsidence of these basins wás recovered during the Cenozoic while half persists to the present. By itself, dynamic topography is incapable of explaining permanent subsidence of sedimentary basins since it is reversible. But it is the reversible nature of dynamic topography which allows us to so easily explain the uplift and exposure of the eastern half of the continent, even as global sea level rises. The linking of the formation of an intracratonic basin (Eromanga) to subduction dynamics may create new opportunities to solve more general problems of enigmatic intracratonic basin subsidence [Sloss, 1990].

The largest scale, Cenozoic subsidence of Australia is not specifically modeled but we believe it is an important clue in deciphering the geodynamics of the Australian plate. This subsidence may be related either to an unusually warm sub Gondwanaland mantle or to the motion of Australia toward the subduction zones presently north of Australia. The Gondwanaland supercontinent was high standing over much of the Phanerozoic [Veevers, 1995] and Africa and East Antarctica today have excessively high hypsometries compared to all other continents [Cogley, 1984]. It is possible that the Gondwanaland mantle was a few 10's of degrees hotter than average mantle and the motion of Australia off the resulting dynamic topography high caused it to subside during the Cenozoic [Gurnis, 1994]. Alternatively, subduction driven global flow models show that Australia could have subsided by about 200 meters since $20 \mathrm{Ma}$ as it moved toward the extensive system of Indonesian and New Guinea subduction [Lithgow-Bertelloni and Gurnis, 1997].

While we are hypothesizing that Australia overrode a subducted slab during the Cretaceous, we note that Australia did not experience a period of volcanism and Laramide-type compression which characterized North America when it over rode the putative flat laying Farallon slab directly beneath the lithosphere [Bird, 1984]. 
Rather, the Jurassic and Early Cretaceous of Australia were typified by a low-relief extensional environment, with no evidence for a high-standing Andean-type magmatic arc. However, further to the east within the interior of N. America, the continent may have overridden a more inclined slab, resulting in a long wavelength downward tilt and subsequent rebound [Mitrovica et al., 1989] as we are now hypothesizing for Australia. The slab beneath Australia was probably much deeper than the slab beneath N. America - in fact best results are obtained when the slab is on average a few hundred kilometers beneath the lithosphere. Moreover, when Australia moved eastward in the direction of the converging margin during the Cretaceous, the margin was probably $\sim 1,000 \mathrm{~km}$ from the continent and consequently we would not expect the slab to be immediately beneath the continental lithosphere.

The same dynamic models are also able to match well the present day geochemistry and geophysics of the Southeast Indian ridge, including the prominent topography on the ridge (Fig. $11 \mathrm{C}$ ), thin crust at $\sim 130^{\circ} \mathrm{E}$ (Fig. 11B), the onset of anomalous tectonics over the last tens of millions of years (Fig. 11B), the sharp jump of an otherwise long wavelength isotopic signature along the ridge and the apparent westward migration of the isotopic anomaly at a few $\mathrm{cm} / \mathrm{yr}$ (Fig. 11B). We imply that the intensity of the dynamic stress (dynamic topography) increased over the last tens of million years, commensurate with the onset of thin oceanic crust, as the cold mantle was advected closer to the surface. This is consistent with the increasing roughness of seafloor topography and development of fracture zone offsets in the AAD over the Neogene [Weissel and Hays, 1974]. However, Marks et al. [1999] have recently shown that residual topography apparently has not increased since $20 \mathrm{Ma}$ while the fracture zone offsets have; our models are probably inconsistent with this observation.

The primary control on the development of anomalous ridge structure by an old slab is the presence of an endothermic phase change at $670 \mathrm{~km}$ depth along with a jump in effective viscosity between transition zone and lower mantle which tends to trap a flat laying slab before the cool mantle is partially drawn upward by the new spreading center beneath the opening Australian and Antarctic plates. Results from seismic tomography and dynamic models have shown that trapping of slabs within the transition zone maybe a common and fundamental attribute of subduction dynamics. This is best displayed beneath the Izu Bonin Arc south of Japan where the slab is flat lying and trapped in the transition zone over a horizontal distance of about 700 $\mathrm{km}$ [van der Hilst and Seno, 1993], much like the structures displayed by the dynamic models (Fig. 8A). In both the mantle and dynamic models, these flat laying structures are best displayed in converging margins which are migrating oceanward in an absolute reference frame [van der Hilst, 1995; Zhong and Gurnis, 1995, 1997] probably identical to the extensional tectonics of the Australian eastern margin during the Cretaceous [Williams and Korsch, 1996].

A substantial body of observational evidence and modeling support our contention that the AAD formed by sampling mantle subjected to long term Mesozoic subduction. This poses the question of whether there are any other regions where a ridge has migrated over a former position of Mesozoic subduction. In Fig. 12 we show the location of Jurassic to Cretaceous subduction fixed with respect to hot spots and present day plate margins. The AAD is clearly unique in being the location where an old subduction zone and a present day ridge are perpendicular to one another. Only ridges associated with back-arc spreading (e.g., on the Scotia and Carribean plates), overlay positions of Mesozoic subduction (Fig. 12). An AAD-like anomaly has been suggested along a western segment of the Pacific-Antarctic ridge at about $185^{\circ} \mathrm{W}$ [Marks and Stock, 1994]. This segment has an axial valley along the ridge, somewhat similar to that along the AAD, and there is a small slope to the depth versus age $\mathrm{e}^{1 / 2}$ relation suggesting lower temperatures within the mantle [Marks and Stock, 1994]. Although this ridge segment does not cross inferred Mesozoic subduction it does meander close to the early Cretaceous position (Figure 12) and overlaps the strong free-air gravity and geoid low of the Ross Sea which may be associated with the overall position of Mesozoic subduction [Chase and Sprowl, 1983].

The model we are proposing for the formation of the AAD is distinctly different from other models particularly recent ones based on isotope geochemistry [West et al., 1997] in which the source of the AAD is actively moving toward the west and driven by mantle flow from the Pacific to Indian Oceans. During the opening of the SEIR the trapped portion of the slab within the transition zone moves little horizontally and the apparent migration is partly due to the motion of the plates toward the east in the hot spot frame and partly due to the initial shallow dip of the subducted slab. The AAD is somewhat similar to the track of a hot spot except here we are dealing with the track of a cold spot. However, the cold region is elongated NS, perpendicular to the ridge and is a 'spot' because the linear cold anomaly 


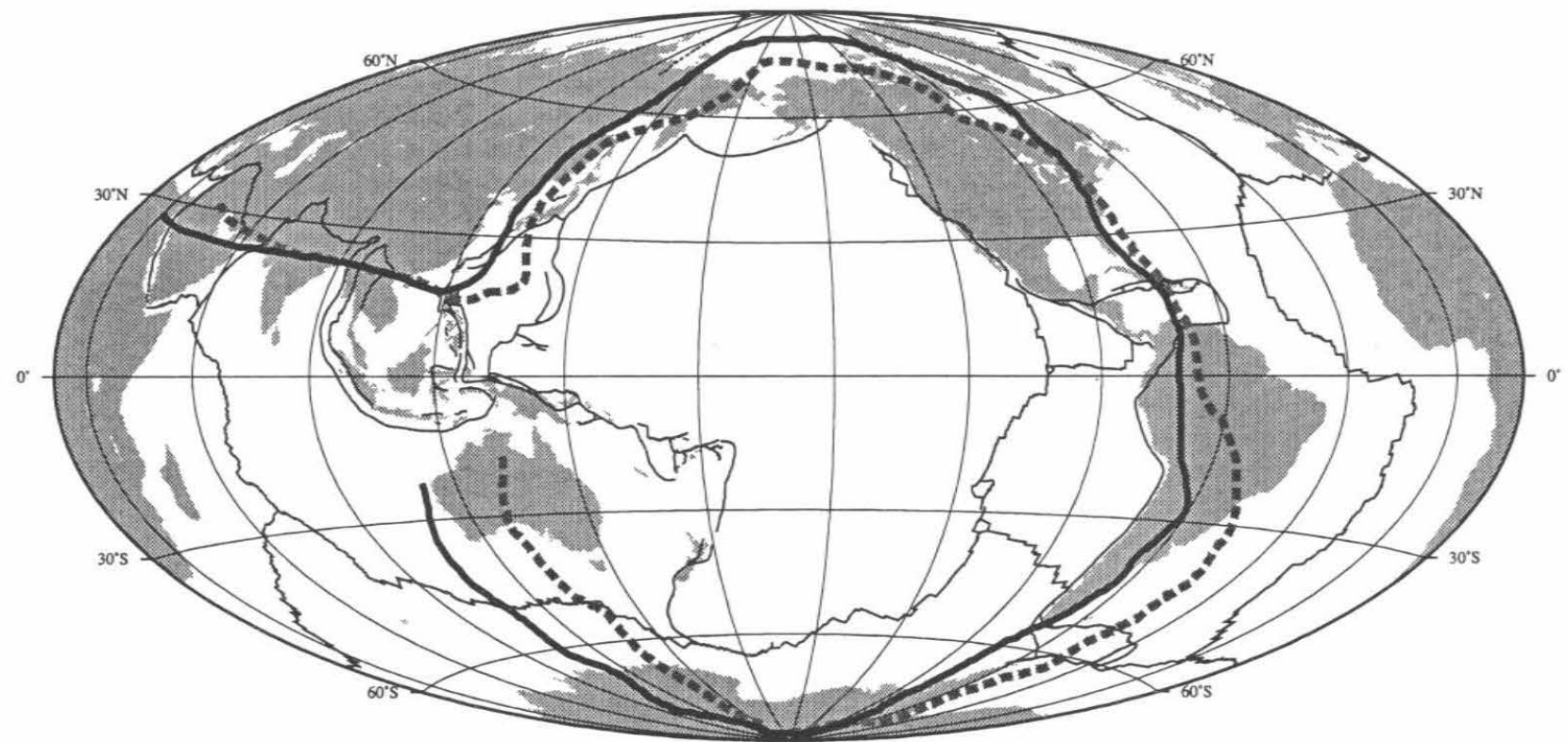

$130 \mathrm{Ma}$

$160 \mathrm{Ma}$

Figure 12. Present day plate bounaries (thin solid line) and present day continental outlines shown along with the inferred position of Early Cretaceous (130 Ma, thick grey dotted line) and Late Jurassic (160 $\mathrm{Ma}$, thick black line) subduction. For $130 \mathrm{Ma}$ the location of trenches is based on Müller et al.'s [1993] absolute plate motion model. The $160 \mathrm{Ma}$ trench locations are based on a preliminary reconstruction derived by assuming that the various present-day hotspots were associated with flood basalts and dike swarms in the Jurassic. In particular this model places the Vema hotspot at the Karoo igenous province, Fernando da Cunha near the central Atlantic dike swarm, and the Bouvet hotspot near the Wedell Sea [L. M. Gahagan, pers. comm.].

and the diverging flow (ridge) are orthogonal. This geometry is substantially different from the interaction of a plume with a ridge. In order to avoid any confusion, it is probably best not to refer to this structure as a cold spot - a 'cold zone' maybe a better term.

Individually, the correspondence between a predicted and observed quantity is not perfect - the importance of our result is the ability to predict a wide suite of disparate observations. These include the subsidence and uplift of Australia during the Cretaceous, the westward migration of an isotopic boundary in the ocean basin, a distinct crustal thickness, isotopic, and topographic structure at the approximate position of the present $\mathrm{AAD}$, and the disruption of the oceanic crust since the start of the Neogene. Mantle or paleogeographic parameters have not been adjusted in order to improve the fit with observed quantities. However, by finding the best match between the wide range of observations and model predictions fundamental constraints can be placed on intrinsic mantle properties (like rheology) and the Mesozoic paleogeography of the Gondwanaland-Pacific margin. Given the strong association between essentially all substantial high seismic velocity mantle anomalies with Mesozoic subduction [Grand et al., 1997], the approach outlined here connecting paleogeography with mantle convection models has wide applicability and can be used to address many problems in continental geology, isotope geochemistry, plate tectonics, and mantle dynamics.

Acknowledgments. We thank H. van Heijst for access to his tomographic models and A. Lenardic, C. Beaumont, and R. Pysklywec for helpful comments on this manuscript. This represents Contribution Number 8577 of the Division of Geological and Planetary Sciences, California Institute of Technology. Some of the work reported here was conducted as 
part of the Australian Geodynamics Cooperative Research Centre and is published with the consent of the Director, AGCRC.

\section{REFERENCES}

Asimow, P. D., A thermodynamic model of adiabatic melting of the mantle, Ph.D. thesis, California Institute of Technology, Pasadena, 1997.

Bird, P., Laramide crustal thickening event in the Rocky Mountain foreland and great plains, Tectonics, 3, 741$758,1984$.

BMR Paleogeographic Group, Cretaceous Paleogeographic Maps, Paleogeographic Series 14, Record 1990/30, Bureau of Mineral Resources, Canberra, 1990.

Bond, G., Evidence for continental subsidence in North America during the late Cretaceous global submergence, Geology, 4, 557-560, 1976.

Bond, G., Speculations on real sea-level changes and vertical motions of continents at selected times in the Cretaceous and Tertiary periods, Geology, 6, 247-250, 1978.

Bradshaw, J., Cretaceous dispersion of Gondwana: continental and oceanic spreading in the south-west PacificAntarctic sector, in Geological evolution of Antarctica, edited by M. R. Thomson, J. A. Crome and J. W. Thomson, pp. 581-585. Cambridge Univ. Pr., 1991.

Brooks, A. N., A Petrov-Galerkin Finite Element Formulation for Convection Dominated Flows, Ph.D. thesis, California Institute of Technology, Pasadena, CA, 1981.

Bryan, S. E., Early Cretaceous volcano-sedimentary successions along the eastern Australian continental margin: Implications for the break-up of eastern Gondwana, Earth Planet. Sci. Lett., 153, 85-102, 1997.

Burgess, P. M., M. Gurnis, and L. Moresi, Formation of sequences in the cratonic interior of North America by interaction between mantle, eustatic and stratigraphic processes, Geol. Soc. Am. Bull., 108, 1515-1535, 1997.

Cande, S. C., and J. C. Mutter, A revised identification of the oldest sea-floor spreading anomalies between Australia and Antarctica, Earth Planet. Sc. Lett., 58, 151$160,1982$.

Chase, C. G., Extension behind island arcs and motions relative to hot spots, J. Geophys. Res., 83, 5385-5387, 1978.

Chase, C. G., and D. R. Sprowl, The modern geoid and ancient plate boundaries, Earth Planet. Sci. Lett., 62, 314$320,1983$.

Christensen, U., Convection with pressure and temperature dependent non Newtonian rheology, Geophys. J., 77, 343$384,1984$.

Cochran, J. R., and M. Talwani, Free-air gravity anomalies in the world's oceans and their relationship to residual elevation, Geophysical Journal, 50, 495-552, 1977.

Cogley, J. G., Deglaciated hypsometry of Antarctica, Earth Planet. Sci. Lett., 67, 284-296, 1984.

Cross, T. A., and R. H. Pilger, Tectonic controls of Late Cretaceous sedimentation, western interior, USA, Nature, 274, 653-657, 1978.

Dalziel, I. W. D., Antarctica: A tale of two supercontinents?, Ann. Rev. Earth Planet. Sci., 20, 501-526, 1992.

Davies, G. F., Mantle convection undersimulated plates: effects of heating modes and ridge and trench migration, and implications for the core-mantle boundary, bathymetry, the geoid and Benioff zones, Geophys. J. R. astron. Soc., 84, 153-183, 1986.

Davies, G. F., Ocean Bathymetry and mantle convection: 2. Small-scale flow, J. Geophys. Res., 93, 10481-10488, 1988.

Davies, G. F., and M. A. Richards, Mantle convection, J. Geol., 100, 151-206, 1992.

Engebretson, D. C., A. Cox, and R. G. Gordon, Relative motions between oceanic and continental plates in the Pacific basin, Geol. Soc. Am. Sp. Paper, 205, 1-59, 1985.

Ewart, A., R. W. Schön, and B. W. Chappell, The Cretaceous volcanic-plutonic province of the central Queensland (Australia) coast - rift related 'calc-alkaline' province, Trans. Roy. Soc. Edinburgh Earth Sci., 83, 327345, 1992.

Exon, N. F., and B. R. Senior, The Cretaceous of the Eromanga and Surat Basins, BMR Journal of Australian Geology and Geophysics, 1, 33-55, 1976.

Forsyth, D. W., R. L. Ehrenbard, and S. Chapin, Anomalous upper mantle beneath the Australian-Antarctic discordance, Earth Planet. Sci. Lett., 84, 471-478, 1987.

Gaina, C., Tectonic history of microplates east of Australia, Ph.D. thesis, The University of Sydney, Sydney, 1998.

Gaina, C., R. D. Müller, J.-Y. Royer, J. Stock, J. Hardebeck, and P. Symonds, The tectonic history of the Tasman Sea: a puzzle with 13 pieces, J. Geophys. Res., 103, 12,41312,433, 1998.

Gallagher, K., Permian to Cretaceous subsidence history along the Eromanga-Brisbane Geoscience Transect, in The Eromanga-Brisbane Geoscience Transect, edited by D. M. Finlayson, no. 232 in Bulletin, pp. 133-151. Bur. Min. Res., Canberra, 1990.

Gallagher, K., and K. Lambeck, Subsidence, sedimentation and sea-level changes in the Eromanga Basin, Australia, Basin Research, 2, 115-131, 1989.

Gallagher, K., T. A. Dumitru, and A. J. W. Gleadow, Constraints on the vertical motion of eastern Australia during the Mesozoic, Basin Resaerch, 6, 77-94, 1994.

Golub, G. H., and C. F. Van Loan, Matrix Computations, Johns Hopkins University Press, Baltimore, 1989.

Grand, S. P., R. D. van der Hilst, and S. Widiyantoro, Global seismic tomography: A snapshot of convection in the Earth, GSA Today, 7(4), 1-7, 1997.

Gurnis, M., Bounds on global dynamic topography from Phanerozoic flooding of continental platforms, Nature, 344, 754-756, 1990.

Gurnis, M., Long-term controls on eustatic and epeirogenic motions by mantle convection, GSA Today, 2, 141-157, 1992.

Gurnis, M., Depressed continental hypsometry behind oceanic trenches: A clue to subduction controls on sea level change, Geology, 21, 29-32, 1993.

Gurnis, M., Epeirogenic motion of Australia in the Mesozoic and Cainozoic: A mantle dynamics perspective, in Geoscience Australia - 1994 and Beyond, Abstracts Number 37, pp. 154-156. Geological Society of Australia, abstract, 1994.

Gurnis, M., R. D. Müller, and L. Moresi, Dynamics of Cretaceous vertical motion of Australia and the AustralianAntarctic discordance, Science, 279, 1499-1504, 1998. 
Hallam, A., Phanerozoic Sea-Level Changes, Columbia University Press, New York, 1992.

Han, L., and M. Gurnis, How valid are dynamic models of subduction and convection when plate motions are prescribed?, Phys. Earth Planet. Int., 110, 235-246, 1999.

Hart, S. R., A large-scale isotope anomaly in the Southern Hemisphere mantle, Nature, 309, 753-757, 1984.

Hughes, T. J. R., The Finite Element Method: Linear Static and Dynamic Finite Element Analysis, PrenticeHall, Inc., Englewood Cliffs, New Jersey, 1987.

Jones, J. G., and J. J. Veevers, Mesozoic origins and antecedents of Australia's Eastern Highlands, J. Geol. Soc. Aust., 30, 305-322, 1983.

King, S. D., Models of mantle viscosity, in Mineral Physics and Crystallography: A Hand Book of Physical Constants, AGU Reference Shelf 2, pp. 227-236. Am. Geophys. Un., 1995.

Klein, E. M., and C. H. Langmuir, Global correlations of ocean ridge basalt chemistry with axial depth and crustal thickness, J. Geophys. Res., 92, 8089-8115, 1987.

Klein, E. M., C. H. Langmuir, A. Zindler, H. Staudigel, and B. Hamelin, Isotope evidence of a mantle convection boundary at the Australian-Antarctic Discordance, $\mathrm{Na}$ ture, 333, 623-629, 1988.

Laird, M., Geological aspects of the opening of the Tasman Sea, in Evolution of the Tasman Basin, edited by G. Van der Lingen, K. Swanson and R. Muir. A. A. Balkema, Rotterdam, 1994.

Langmuir, C. H., E. M. Klein, and T. Plank, Petrological systematics of mid-ocean ridge basalts: Constraints on melt generation beneath ocean ridges, in Mantle Flow and Melt Generation, edited by J. Phipps Morgan, D. K. Blackman and J. M. Sinton, 71, Geophysical Monograph, pp. 183-280. American Geophysical Union, Washington, D.C., 1992.

Lecroart, P., A. Cazenave, Y. Ricard, C. Thoraval, and D. G. Pyle, Along-axis dynamic topography constrained by major-element chemistry, Earth Planet. Sci. Lett., 149 , 49-56, 1997.

Lithgow-Bertelloni, C., and M. Gurnis, Cenozoic subsidence and uplift of continents from time-varying dynamic topography, Geology, 25, 735-738, 1997.

Mammerickx, J., and D. Sandwell, Rifting of old oceanic lithosphere, J. Geophys. Res., 91, 1975-1988, 1986.

Marks, K. M., and J. M. Stock, Variations in ridge morphology and depth-age relationships on the Pacific-Antarctic ridge, J. Geophys. Res., 99, 531-541, 1994.

Marks, K. M., J. M. Stock, and K. J. Quinn, Evolution of the Australian-Antarctic discordance since Miocene time, J. Geophys. Res., 104, 4967-4981, 1999.

McClain, J. S., and C. A. Atallah, Thickening of the oceanic crust with age, Geology, 14, 574-576, 1983.

McKenzie, D. P., J. M. Roberts, and N. O. Weiss, Convection in the Earth's mantle: towards a numerical simulation, J. Fluid Mech., 62, 465-538, 1974.

Mitrovica, J. X., C. Beaumont, and G. T. Jarvis, Tilting of continental interiors by the dynamical effects of subduction, Tectonics, 8, 1079-1094, 1989.

Moresi, L., and M. Gurnis, Constraints on the lateral strength of slabs from three-dimensional dynamic flow models, Earth Planet. Sci. Lett., 138, 15-28, 1996.
Moresi, L., S. Zhong, and M. Gurnis, The accuracy of finite element solutions of Stokes' flow with strongly varying viscosity, Phys. Earth Planet. Int., 97, 83-94, 1996.

Moresi, L. N., and V. S. Solomatov, Numerical investigation of $2 \mathrm{D}$ convection with extremely large viscosity variations, Phys. Fluid, 7, 2154-2162, 1995.

Müller, R., D. Mihut, and S. Baldwin, A new kinematic model for the evolution of the West and Northwest Australian margin, in West Australian Basins Conference, edited by P. Purcell and R. R. Purcell, Perth. Petroleum Exploration Society of Australia, 1998.

Müller, R. D., J.-Y. Royer, and L. A. Lawver, Revised plate motions relative to the hotspots from combined Atlantic and Indian hotspot tracks, Geology, 21, 275-278, 1993.

Müller, R. D., U. R. Roest, J.-Y. Royer, L. M. Gahagan, and J. G. Sclater, Digital isochrons of the world's ocean floor, J. Geophys. Res., 102, 3211-3214, 1997.

Paine, A. G. L. (ed.), Australia: Evolution of a Continent, Bureau of Mineral Resources, Australia, Canberra, 1990.

Press, W. H., B. P. Flannery, S. A. Teukolsky, and W. T. Vetterling, Numerical Recipes in C, Cambridge University Press, New York, 2nd edn., 1992.

Pribac, F., Superswells Due to Mantle Convection, Ph.D. thesis, Australian National University, Canberra, 1991.

Pyle, D. G., M. Christie, D, and J. J. Mahoney, Resolving an isotopic boundary within the Australian-Antarctic discordance, Earth Planet. Sci. Lett., 112, 161-178, 1992.

Ranalli, G., Rheology of the Earth, Chapman and Hall, New York, 2nd edn., 1995.

Rehkämper, M., and A. W. Hofmann, Recycled ocean crust and sediment in Indian Ocean MORB, Earth Planet. Sci. Lett., 147, 93-106, 1997.

Richards, M. A., and B. H. Hager, Geoid anomalies in a dynamic Earth, J. Geophys. Res., 89, 5987-6002, 1984.

Russell, M., and M. Gurnis, The planform of epeirogeny: Vertical motions of Australia during the Cretaceous, Basin Research, 6, 63-76, 1994.

Schroeder, W., The empirical age-depth relation and depth anomalies in the Pacific Ocean basin, J. Geophys. Res., 89, 9873-9884, 1984.

Sloss, L. L., Tectonic evolution of the craton in Phanerozoic time, in Sedimentary Cover - North American Craton: U. $S$., edited by L. L. Sloss, The Geology of North America D-2, pp. 25-51. Geological Society of America, Boulder, 1988.

Sloss, L. L., Epilog, in Interior Cratonic Basins, edited by M. W. Leighton, D. R. Kolata, D. F. Oltz and J. J. Eidel, Memoir 51, pp. 799-805. The American Association of Petroleum Geologists, Tulsa, 1990.

Struckmeyer, H. I. M., and P. J. Brown, Australian Sealevel Curves Part 1: Australian Inundation Curves, Record 1990/11, Bureau of Mineral Resources, Canberra, 1990.

Symonds, P., J. B. Colwell, H. Struckmeyer, J. Willcox, and P. Hill, Mesozoic rift basin development off eastern Australia, in Mesozoic Geology of the Eastern Australia Plate, in Mesozoic Geology of the Eastern Australian Plate Conference, Extended Abstracts No. 43, pp. 528-542, Sydney. Geological Society of Australia, 1996.

Tolstoy, M., A. J. Harding, J. A. Orcutt, and J. Phipps Morgan, Crustal thickness at the Australian Antarctic discordance and neighboring South East Indian ridge, in EOS 
Fall Meeting Supplement, 76, p. 570. 1995.

Tulloch, A., and D. L. Kimbrough, The Paparoa metamorphic core complex, New Zealand: Cretaceous extension associated with fragmentation of the Pacific margin of Gondwana, Tectonics, 8, 1217-1234, 1989.

van der Hilst, R., Complex morphology of subducted lithosphere in the mantle beneath the Tonga trench, Nature, 374, 154-157, 1995.

van der Hilst, R., and T. Seno, Effects of relative plate motion on the deep structure and penetration depth of slabs below the Izu-Bonin and Mariana island arcs, Earth Planet. Sci. Lett., 120, 395-407, 1993.

van der Hilst, R. D., S. Widiyantoro, and E. R. Engdahl, Evidence for deep mantle circulation from global tomography, Nature, 386, 578-584, 1997.

Van der Voo, R., Paleomagnetism of the Atlandtic, Tethys and Iapetus Oceans, Cambridge University Press, New York, 1993.

van Heijst, H. J., New constraints on the seismic structure of the Earth from surface wave overtone phase velocity measurements, Ph.D. thesis, University of Oxford, 1997.

Veevers, J. J., Australian-Antarctic depression from the mid-ocean ridge to adjacent continents, Nature, 295, 315317, 1982.

Veevers, J. J. (ed.), Phanerozoic Earth History of Australia, Clarendon Press, Oxford, 1984.

Veevers, J. J., Emergent, long-lived Gondwanaland vs. submergent, short-lived Laurasia: Supercontinental and Pan-African heat imparts long-term buoyancy by mafic underplating, Geology, 23, 1131-1134, 1995.

Watts, A. B., and M. Steckler, Subsidence and eustasy at the continental margin of eastern North America, in Deep Drilling Results in the Atlantic Ocean: Continental Margins and Paleoenvironments, edited by M. Talwani and W. Hays, Maurice Ewing Series 3, pp. 218-234. American Geophysical Union, Washington, D.C., 1979.
Weissel, J. K., and D. E. Hayes, The Australian-Antarctic Discordance: New Results and Implications, J. Geophys. Res., 79, 2579-2587, 1974.

West, B. P., S. D. Wilcock, J.-C. Sempére, and L. Géli, Three-dimensional structure of asthenospheric flow beneath the Southeast Indian Ridge, J. Geophys. Res., , 102, 7783-7802, 1997.

Williams, N., and R. Korsch, The Mesozoic geology of the eastern Australian plate, in Mesozoic Geology of the Eastern Australian Plate Conference, Extended Abstracts No. 43, pp. 564-568, Sydney. Geological Society of Australia, 1996.

Zhong, S., and M. Gurnis, Mantle convection with plates and mobile, faulted plate margins, Science, 267, 838-843, 1995.

Zhong, S., and M. Gurnis, Interaction of weak faults and Non-Newtonian rheology produces tectonic plates in $3 \mathrm{D}$ model of mantle flow, Nature, 383, 245-247, 1996.

Zhong, S., and M. Gurnis, Dynamic interaction between tectonic plates, subducting slabs, and the mantle, Earth Interactions, 1(6), http://EarthInteractions.org/, 1997.

Zhong, S., M. Gurnis, and G. Hulbert, Accurate determination of surface normal stress in viscous flow from a consistent boundary flux method, Phys. Earth and Planet. Int., $78,1-8,1993$.

M. Gurnis, Seismological Laboratory, California Institute of Technology, Pasadena, CA 91125. (email: gurnis@caltech.edu)

L. Moresi, Australian Geodynamics Cooperative Research Centre, CSIRO Exploration and Mining, Nedlands, WA 6009 Australia. (e-mail: louis@ned.dem.csiro.au)

R. Dietmar Müller, Department of Geology and Geophysics, The University of Sydney, Sydney, NSW 2006, Australia. (e-mail: dietmar@es.su.oz.au) 